This PDF is a selection from a published volume from the National Bureau of Economic Research

Volume Title: The Economics of School Choice

Volume Author/Editor: Caroline M. Hoxby, editor

Volume Publisher: University of Chicago Press

Volume ISBN: 0-226-35533-0

Volume URL: http://www.nber.org/books/hox03-1

Conference Date: February 22-24, 2001

Publication Date: January 2003

Title: Neighborhood Schools, Choice, and the Distribution of Educational Benefits

Author: Dennis N. Epple, Richard Romano

URL: http://www.nber.org/chapters/c10090 


\title{
Neighborhood Schools, \\ Choice, and the Distribution of Educational Benefits
}

\author{
Dennis Epple and Richard Romano
}

\subsection{Introduction}

In this chapter, we examine the implications of a neighborhood system of public schooling and compare it to provision that allows districtwide open enrollment or choice. We also contrast these policy regimes with the most decentralized form of direct public educational provision, in which neighborhoods constitute their own school districts. This study is part of a research agenda that investigates school choice and finance policies. We begin by outlining our research findings to date in order to place the results developed below in the broader context of our conception of alternative educational policies and their consequences.

Our research emphasizes differences in attributes of students and their households (especially in student ability and household income), peer groups in schools and in the classroom, equilibrium sorting of types of students within the schooling system, and the consequences for school qualities and the distribution of educational benefits. Although variation in schooling expenditure plays a role, because schooling quality is substantially determined by student peer groups, we find that significant hetero-

Dennis Epple is the Thomas Lord Professor of Economics at Carnegie Mellon University and a research associate of the National Bureau of Economic Research. Richard Romano is the Gerald L. Gunter Professor of Economics at the University of Florida.

An earlier version of this paper was titled "Public School Choice and Finance Policies, Neighborhood Formation, and the Distribution of Educational Benefits." The authors thank David N. Figlio, Jon Hamilton, Eric A. Hanushek, Caroline M. Hoxby, Michael Kremer, Steve Slutsky, David E. Wildasin, two anonymous referees, and seminar participants at the University of British Columbia, the University of Montreal, Stanford University, the 1995 National Bureau of Economic Research (NBER) School Finance Workshop, and the 1996 American Association Meetings for comments. This research is supported by NBER, the National Science Foundation, and MacArthur Foundation, with our gratitude. 
geneity in schools and outcomes results even under policies that equalize finance or if expenditure variation has small effects.

In our research, we have developed a theoretical model of students and their households and of related educational institutions that makes simple assumptions. For example, we presume that households with a school-age child obtain higher utility as their child's educational achievement increases, and attendance at a higher-quality school increases that achievement. Our model is detailed below. Our intent in focusing on simple characteristics in developing the model is to allow the flexibility to analyze the variety of educational policy alternatives that exist and have been proposed. Given a policy regime, we predict consequences for schooling qualities and educational outcomes. We quantify and illustrate these predictions with a computational model that complements the theoretical model. The computational model specifies functional forms for components of the model like the household utility function, and its parameters are calibrated to a variety of empirical findings.

Most of the theoretical components of our model are part of received theory. However, we must make assumptions about what the crucial elements of the educational process are, including assumptions about issues lacking definitive empirical evidence, and, in calibrating the computational model, we can rely only on the best available estimates. The most important of these assumptions we make is that a student's educational achievement is influenced by the student's peer group in school. For these reasons, it is important that predictions of the model be tested. Although Epple, Figlio, and Romano (forthcoming) provide evidence that supports the basic model, more such testing remains to be done. We focus on developing predictions in this chapter.

Our research predicts that the nature of student sorting into schools and the consequences for school qualities and educational outcomes are dramatically influenced by public policy. This is illustrated by the three panels of figure 7.1, which depict student sorting into schools under three different policy regimes. Abstracting from detail that is developed later in the chapter, our model characterizes households as having exogenous income $(y)$ and one student with ability level denoted $b$. Households value the educational achievement of their child, which rises with the quality of the school attended and the child's own ability. School quality is determined at least in part by the distribution of student ability in the school, with higher-ability students improving school quality for all through a peer-group effect. Higher-income households are willing to pay more for increases in their child's educational achievement and hence are willing to pay more for increases in the quality of their child's school. The set of households is characterized by a joint distribution over income and ability, which we will usually assume to exhibit positive correlation (for several reasons to be discussed). 
A

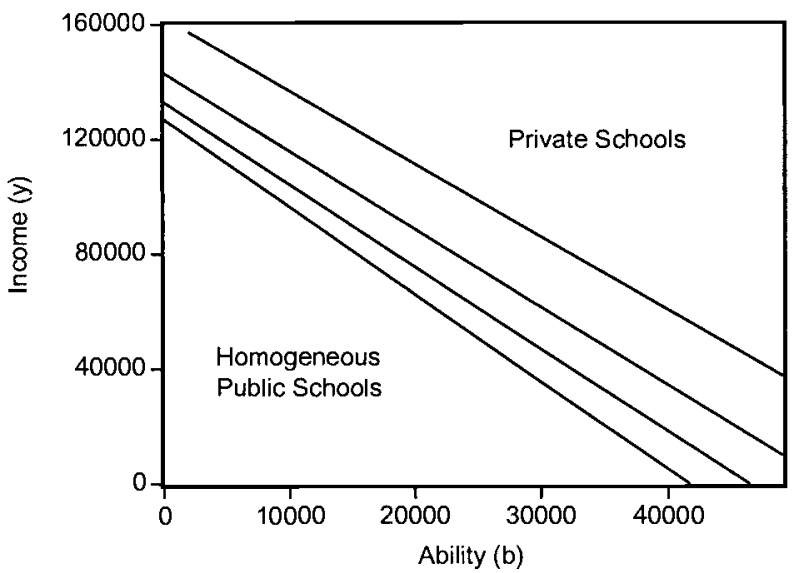

B

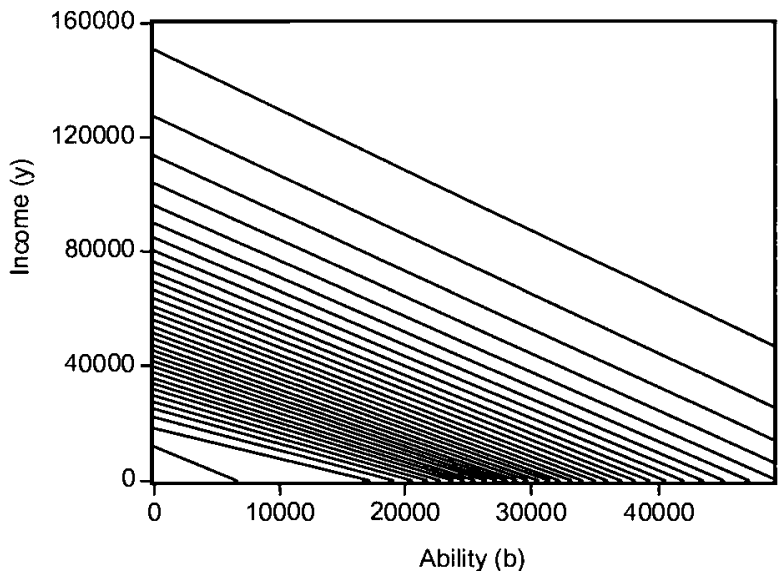

C

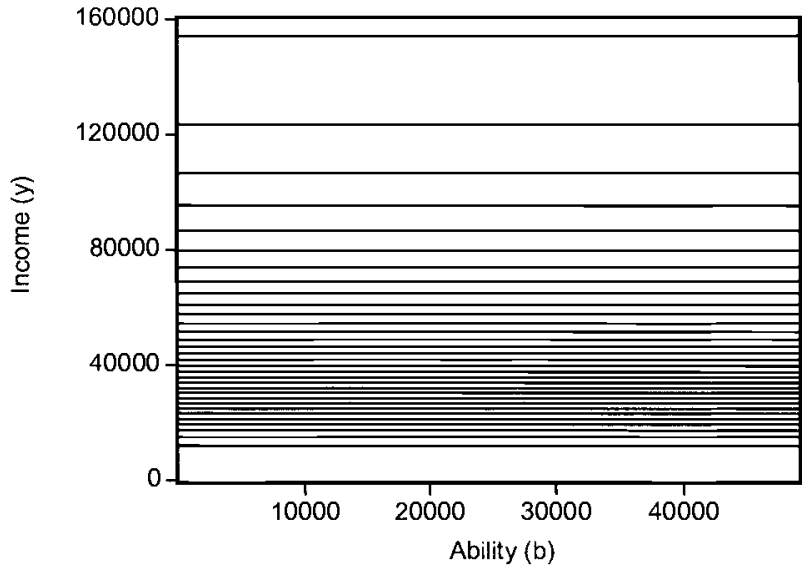

Fig. 7.1 $A$, Admission spaces with no voucher; $B$, admission spaces with a flat-rate per-student voucher of $\$ 4,200$ (all private schools); $C$, admission spaces for a neighborhood school system 
The panels of figure 7.1 show how the "type space of students," that is, the ability-income plane, is partitioned into schools in equilibrium under three different policy regimes. In each of these cases there is only one (large) school district, or a single political jurisdiction, that determines educational expenditure per student in public schools. In panel A, there is open enrollment in the public sector, meaning that students may choose any (free) public school so long as they live in the district, and there is a competitive (free entry) private sector. In equilibrium, here public schools are homogeneous and serve a large population consisting of relatively nonaffluent and lower-ability students, those that make up the triangle with vertex at the origin. The upper diagonal lines, which we call "boundary loci," delineate the student bodies of four private schools that arise in the equilibrium. The private school that serves the most affluent and highest-ability set of students is of highest quality, due to its having the highest-ability peer group (and perhaps higher per-student expenditure). The private schools as one moves southwest in panel A decline in quality, but all are of higher quality than the homogeneous public-sector schools. Private schools charge tuition that varies with ability and, to some extent, with income. Private schools give tuition discounts to higher-ability students because they increase the quality of the school through the peer-group effect on education, thus allowing the school to charge everyone higher tuition. Very high ability students may pay zero tuition or receive fellowships. The discounting to ability combined with increased demand for quality with income leads to a cross-subsidization within schools from the relatively higher-income and lower-ability students to the opposite types of students-hence the partition with downward-sloping boundary loci. As either income or ability itself increases, students find themselves in better schools. We refer to the latter respectively as income and ability stratification. Students must be of sufficiently high income or ability (or some combination) to find themselves in a private school.

Panel B depicts an equilibrium with only private schools serving students. Such a system would obviously arise if public policy provides no public option, but it also would arise if all households have access to a voucher of magnitude equal to at least average school cost. In the latter case, no students choose the public option. Private schools behave as in panel A, the difference being that there are many private schools and a wider distribution of schooling qualities. The differences in peer groups and school qualities between students near the origin and far out in the ability-income plane are substantial.

Panel $\mathrm{C}$ depicts an equilibrium with no private schools (as if they are illegal or unable to cover their costs), but with the single district divided into small neighborhoods, each of which has its own school. Here, public policy requires that a household send its child to school in the neighborhood in which the household resides. This equilibrium presumes, as could be in the 
other cases in figure 7.1, that demand for schooling quality is independent of student ability but that household income and student ability are positively correlated. Although per-student expenditure is the same across the schools since this is within one district, the income stratification and income-ability correlation lead to a hierarchy of public school qualities via the peer effect. The quality hierarchy is supported by rising housing prices across neighborhoods with school qualities, and selection of higher-income households into neighborhoods with better schools. Although it appears that households are stratified only by income in panel $\mathrm{C}$, average student ability rises as neighborhoods become more wealthy due to the correlation between income and ability.

We see that the three policy regimes have substantially different predictions about the equilibrium allocation. These three policy alternatives vividly illustrate that the effects of school choice policies vary dramatically with the specifics of the policy. Panel A presumes open enrollment in the public sector, or that there is public-school choice. Panel B corresponds to a universal voucher system with vouchers of sufficient magnitude that everyone chooses a private school. There are many other "choice policies," several of which are discussed later, also with different predicted outcomes. It bears emphasis that school choice policies can be expected to have (sometimes) radically different implications for equilibrium provision of schooling, a theme of this paper and volume.

From a research standpoint, differences in predictions across educational policies provide a means to test the model: Although both a neighborhood schooling regime and private schooling are associated with income stratification across schools, only the latter exhibits ability stratification for given income. Hence, for example, our model predicts that vouchers or lower entry barriers on private schools will increase ability stratification.

Detailed analysis of the regimes in panels A and B are in Epple and Romano $(1998,1999)$. Epple and Romano (1998) develop the analysis with no vouchers and with flat-rate (or universal) vouchers. Epple and Romano (1999) investigate voucher design, allowing vouchers to be conditioned on student attributes and, perhaps, characteristics of the school attended. In this chapter we develop properties and attendant predictions of the equilibrium that is depicted in panel $\mathrm{C}$, as well as investigating the effects of a public-school choice policy. ${ }^{1}$ We will also in section 7.6 return to a more detailed comparison of neighborhood public schooling provision to voucherinduced private provision.

This chapter proceeds as follows. The next section motivates our study of neighborhood schooling and public-school choice, provides an overview of

1. Epple, Newton, and Romano (2002) investigate the equilibrium causes and consequences of ability tracking in schools, hence the interaction of sorting of students within and across schools. 
the related results, and discusses related literature. Section 7.3 presents the theoretical model, and section 7.4 develops the theoretical predictions. Section 7.5 details the computational analysis, including normative findings. Section 7.6 further contrasts the neighborhood equilibrium with the private-provision alternative. Section 7.7 draws conclusions. Some of the more technical analysis is in the appendix.

\subsection{Neighborhood Schooling, the Choice Movement, and an Overview}

Public education in the United States is increasingly characterized by centralized finance but with schools determined by neighborhood of residence. Within jurisdictions, households frequently may choose among neighborhoods in which to reside and send their children to school, but with limited opportunity to choose alternative tax-expenditure schooling packages. In 1998, nine states had school districts that were coterminous with counties or very nearly so, and the ratio of school districts to counties was 2 or below in four more states. ${ }^{2}$ Since counties are relatively large geographic entities, county districts are typically multischool districts. Moreover, these thirteen states do not include a number of states that have the lowest variation among districts in expenditure per student due to relatively centralized finance systems. Examples are Delaware, Colorado, and California, whose ratios of 95 th percentile to 5 th percentile district expenditures in 1994 were, respectively, 1.26, 1.31, and 1.34. ${ }^{3}$ Although uneven and of limited success, a central theme in educational finance reform over the last several decades has been expenditure equalization. ${ }^{4}$ For example, the same district expenditure ratios in 1972 for the three states just mentioned were, respectively, 1.81, 1.61, and 1.95. ${ }^{5}$ Most students live in districts with multiple schools: In 1993-94, 91 (66) percent of elementary- (high-)school students lived in districts with multiple elementary (high) schools (U.S. Department of Education 1994). Although there is a growing trend toward centralization of finance in the United States, centralization of finance is al-

2. The first nine states are Hawaii, Maryland, West Virginia, Nevada, Florida, Louisiana, Georgia, Virginia, and North Carolina, and the second four states are Tennessee, Utah, Alabama, and Mississippi. These data are from the Common Core of Data for 1998.

3. These calculations use data from the Census of Governments for 1972 and the Common Core of Data for 1994. The ratios for these years have been calculated for forty-five states, excluding Hawaii (whose ratio is 1), Alaska, Arkansas, Montana, and Vermont. Districts are nonunified in the latter three states and were exempted from the calculations. Special thanks to David Figlio for providing access to his database.

4. See Gold, Smith, and Lawton (1995) for state-by-state description of their school finance system and summary of reforms and initiatives.

5. Among the forty-five states for which calculations were made (see footnote 3 ), the change from 1972 to 1994 of the 95th percentile to 5th percentile district expenditure ratio exceeded 10 percent (of the 1972 ratio) in eighteen states. In sixteen of these states the ratio declined. The exceptions are Maine and Missouri. See Murray, Evans, and Schwab (1998) for evidence that court cases have substantially reduced expenditure inequality. 
ready well established in many other countries (Benabou 2000). Analysis of the provision of education using a standard Tiebout model with community-level finance of education is inappropriate in such settings. One purpose of this chapter is to examine neighborhood formation and schooling provision when no choice among political jurisdictions is practical but choice among neighborhoods within the jurisdiction can be exercised. Here any neighborhood sorting of households and variation in school quality that result are driven solely by peer-group effects.

As school finance is under reform in the United States, a school choice movement is gaining momentum. ${ }^{6}$ Choice policies and proposals include inter- and intradistrict open enrollment, formation of magnet and charter schools, and vouchers for private schools. The United States is by no means at the forefront of this movement. For example, broad school choice reforms were adopted in the United Kingdom in the early 1980s. It remains to be seen how the school choice movement will evolve, but it seems likely that some form or forms of increased school choice will play a role in the future. Another purpose of this chapter is to investigate the effects of publicschool choice. We examine the consequences of elimination of territorial (neighborhood) restrictions on school attendance in our model, with and without friction in the exercise of school choice. ${ }^{7}$

We develop a theoretical and complementary computational model to study equilibria in the aforementioned policy regimes, with attention to the distribution of educational benefits. School quality is presumed to depend both on per-student educational expenditure and on the makeup of the student body, the latter measured by mean student ability. Households differ continuously by income and student ability, with normal demand for educational quality. The economy is made up of an exogenous number of neighborhoods, each having a school and with given housing supply. Households choose in which neighborhood to reside and where to send their child to school as constrained by policy, and vote over the economy's tax expenditure package. With neighborhood schooling, students must attend school in their neighborhood of residence. With choice, students may attend school in another neighborhood, which may or may not entail a private (transportation) cost. We also compare these equilibria to that of the tradi-

6. Probably the biggest recent story is Florida's statewide voucher program for students in failing public schools introduced in the 1999-2000 academic year. However, there are a myriad of choice programs and initiatives. See Rees (2000) for a recent state-by-state summary.

7. The U.S. Department of Education National Center for Educational Statistics (1996) estimated that 13.8 percent of U.S. school districts had intradistrict open enrollment policies and 28.6 percent of districts were subject to interdistrict open enrollment policies in 1993-94. Participation of students subjected to the respective policies was 24.5 percent and 1.6 percent respectively. The estimated rate of "participation" in intradistrict policies must be interpreted with care, because some programs require households to choose their school, with then 100 percent participation rate. More generally, programs differ in limitations and requirements. See Rees (2000) for details and sources for more information. 
tional Tiebout environment, where neighborhoods provide schooling only to their residents, who then also collectively determine their neighborhood's tax-expenditure package.

The main predictions are as follows. Neighborhood schooling is enough to lead to stratified equilibrium and a school-quality hierarchy if ability and income are positively correlated or if demand for school quality rises with student ability. Thus, a stratified outcome typically arises even though there is no variation in per-student expenditure across schools. Why? Peer student abilities are a key determinant of school quality in our model. Thus, households who demand higher school quality will pay a housing price premium to live in neighborhoods with schools having a higher-ability student peer group. If demand for educational quality rises with income, as we assume, then households will stratify by income across schools, with higherincome households occupying neighborhoods with higher-quality schools. This income sorting in turn sustains the school quality hierarchy via the positive correlation between income and student ability. If demand for school quality also rises with ability, as in some specifications we consider, equilibrium continues to be characterized by a hierarchy of school qualities, and there is stratification by both income and ability across the school hierarchy.

The equilibrium described in the preceding paragraph is supported by housing prices that ascend across neighborhoods in the same order as school quality. If we introduce intradistrict choice across public schools and there are no costs of exercising this choice (e.g., if transportation costs are paid by the government), then schooling qualities will be equalized in equilibrium. With the linkage between residence and school severed, housing prices cannot ration access to higher-quality schools. Equilibrium is characterized by equal-quality schools, each with the same student peer groups, and no housing price differences across neighborhoods. There are also secondary effects on the equilibrium school expenditure level, and results vary some when costs of exercising choice are present, as we will later show.

The (former) single-district equilibrium with neighborhood schools of different qualities is comparable to another no-choice policy in which neighborhoods constitute their own districts that individually select school tax-expenditure levels. Although this alternative does lead to differences in expenditure levels across neighborhoods, it does not alter much (if at all) the sorting of households and students into neighborhoods and schools. Given that peer effects are important, what is fundamental to sorting into neighborhoods and schools is a residence requirement for school placement, which characterizes both a single-district neighborhood system and a multidistrict local-finance system. An implication that we emphasize is that expenditure equalization, a popular reform intended to equalize schooling quality, will itself fail miserably to "equalize" peer groups and thus school qualities (given the importance of peer effects). Moreover, we will provide 
clear evidence that sorting across neighborhoods and schools within large districts is extreme.

School choice engendered by a universal and laissez-faire voucher system with vouchers of sufficient magnitude that all schooling is provided privately also eliminates any role that residence has on school attendance. However, such a voucher system is predicted to yield a highly stratified equilibrium, much closer to the multidistrict public equilibrium than to the single-district, public-school choice equilibrium. Here the market will provide households with what they want, given their incomes (and the voucher supplement), while rewarding student ability because it is an input to educational quality through the peer effect. Higher-income households with lower-ability students will buy their way into private schools by supplementing the voucher. Higher-ability students, whether of high or low income, will be drawn into private schools with tuition subsidies provided by schools on top of the voucher, including fellowships in some cases. The result will be an equilibrium stratified by both income and ability across schools (but not neighborhoods), with more ability stratification than under the no-choice, public-schooling equilibria because of the latitude of the private schools to use financial aid to attract higher-ability students. As will be discussed further, limits on the practices of private schools that may be associated with alternative voucher systems can radically alter the predicted allocation. This is but another example of the truism "all choice programs are not alike."

Before turning to the analysis, we comment briefly on related literature. Our analysis is in the tradition of multicommunity models of local public good provision begun by Tiebout (1956). ${ }^{8}$ A number of papers study provision of public education in such a framework, including Inman (1978), de Bartolome (1990, 1997), Glomm and Ravikumar (1992), Benabou (1993, 1996), Silva and Sonstelie (1995), Durlauf (1996), Fernandez and Rogerson (1996, 1997a, 1997b, 1998), and Nechyba (1999, 2000). Central to our model are peer effects, which play a role only in de Bartolome (1990), Benabou (1993, 1996), Durlauf (1996), and Nechyba (1999, 2000) among the latter list. Further narrowing the overlap, only Benabou $(1993,1996)$ has an analogue to neighborhood provision of schooling within a jurisdiction. ${ }^{9}$ In results similar to one of "our" findings, he shows that complementarities in

8. See Ellickson (1971); Westhoff (1977); Epple, Filimon, and Romer (1984); Goodspeed (1989); Epple and Romer (1991); Fernández (1997); Brueckner (2000); and the papers that focus on schooling discussed next.

9. Nechyba's jurisdictions are divided into neighborhoods that differ by their qualities of housing, but public school students in all neighborhoods within a jurisdiction attend the same school. Hence, he finds stratification by income across neighborhoods within jurisdictions but not across public schools within a jurisdiction. Stratification in public schooling quality across jurisdictions arises, however, including when there is statewide finance. In the latter case, the role of a jurisdiction is similar to the role of a neighborhood in our paper, and school-quality stratification arises similarly. 
individual and group characteristics can lead to community stratification without expenditure differences. The models and emphasis differ substantially. Other related research is noted at various points during the chapter.

\subsection{The Model}

Each household has one child of ability $b$ who will attend public school. Household income is denoted $y$. The population of households is normalized to one and characterized by joint probability density function $f(b, y)$, with $f(b, y)$ continuous and strictly positive on its support $S \equiv\left[b_{m}, b_{x}\right] \times\left[y_{m}\right.$, $\left.y_{x}\right] \subset R_{+}^{2}$. Whether income and ability are correlated in the population is important. To simplify, we assume that $E[b \mid y]$ is either strictly increasing in $y$ or independent of $y$, implying either positive or zero correlation.

Household utility depends on numeraire and housing consumption, and the educational achievement of the child denoted $a$. Every household consumes exactly one unit of housing at price denoted $p$, the simple housing market discussed further later. The student's educational achievement depends on the quality, $q$, of the school attended, and on the student's ability: $a=a(q, b)$. School quality depends on per-student educational expenditure in the school, $X$, and on the mean ability of the school's peer group, denoted $\theta$. The latter peer-group effect in education is central to our model and will be discussed further. Educational expenditure is financed by a proportional income tax, $t$. Given that a unit of housing is consumed, utility is then given by $U=U[y(1-t)-p, a(q(X, \theta), b)]$, with all functions increasing, continuous, and differentiable. Demand for educational quality is assumed normal:

$$
\frac{U_{q}}{U_{y}} \text { increases with } y \text {. }
$$

In much of the analysis we employ a Cobb-Douglas utility-achievement specification:

$$
U=[y(1-t)-p] X^{\alpha} \theta^{\gamma} b^{\beta} ; \quad q=X^{\alpha} \theta^{\gamma} ; \quad a=q b^{\beta} ; \quad \alpha, \gamma, \beta>0 .
$$

The economy consists of $N \in\{2,3, \ldots\}$ neighborhoods, with exogenously defined boundaries and with one school in every neighborhood. Each neighborhood has a backward-L housing supply, horizontal at magnitude $c$ until neighborhood land capacity is reached. Interpret $c$ to be the construction cost of a unit of housing, with each housing unit requiring one lot of land. For now, assume the economy land capacity is exactly enough to house the population. We offer a more appealing interpretation later, but it can introduce additional equilibria that we wish to avoid initially.

Households make a residence choice, choose a school for their child, and participate in a vote over tax rates. The nature of these choices depends on a binary policy parameter that we vary exogenously. The choice of school 


\begin{tabular}{|c|c|c|c|}
\hline $\begin{array}{l}\text { Residence Choices } \\
\text { \& Housing Markets } \\
\text { Clear }\end{array}$ & $\rightarrow$ & Schools Chosen & $\rightarrow$ \\
\hline
\end{tabular}

\section{Fig. 7.2 Order of activities}

may or may not be restricted by a neighborhood residence requirement. A residence requirement implies that attendance is restricted to one's neighborhood school so that the school's peer group corresponds to that of the children of neighborhood residents. Of course, the absence of such a requirement permits real school choice, and this is what we mean by a schoolchoice or open-enrollment policy. We will consider the effects of a school choice policy with and without any frictions (costs of exercising choice).

As motivated above, we focus on the case in which school finance is centralized. A single income tax rate is determined by majority preference in the entire economy here under centralized finance. Constant returns to scale in schooling are assumed, implying that per-student expenditure in the economy is invariant in this case. This conforms to cases with districtlevel finance and large enough districts that nonschool factors determine district choice, or to some cases with statewide finance. ${ }^{10}$ For purposes of comparison, we will also examine the more traditional Tiebout public finance problem with multiple political jurisdictions by assuming that neighborhoods correspond to jurisdictions.

Equilibria are determined assuming the timing of activities summarized in figure 7.2. In the first stage, (atomistic) households make neighborhood residence choices as price takers and the housing markets clear. Households then choose a school, although a residence requirement renders this choice a given. Voting over taxes takes place last, voters taking the (now committed) residences and schools as given. ${ }^{11}$ The model has a single period; no real time elapses between the stages. Households correctly anticipate the ensuing properties of equilibrium when making choices, of course.

10. The model applies precisely to statewide finance if households are exogenously assigned to regions (e.g., by employment opportunities), and regions are homogeneous with regard to their distribution of household types and their neighborhoods' housing supplies. Alternatively, the model applies precisely if choice of neighborhood in the entire state is determined by schooling. These are obviously very strong assumptions, but they are needed only to be consistent with the model's determination of voting equilibrium. Key results like stratification across neighborhoods require only that expenditure is constant across neighborhoods, and then would hold for appropriately modified determination of voting equilibrium.

11. Perhaps surprisingly, if voting occurs in the second stage and school choice is last, all results below are correct as long as equilibrium exists under this alternative. This is because, for one subset of cases we study, the exercise of choice does not vary with the tax; and, for the remaining cases, the preferred tax of voters is (locally) independent of anticipated variation in the exercise of choice. The problem with the alternative timing is that existence of voting equilibrium is not guaranteed in the latter cases, leading us to adopt the timing in figure 7.1. We developed the results with the alternative timing in an earlier version of this paper (Epple and Romano 1995) while simply assuming existence. 
Some elements of the model warrant further discussion. School quality is determined in part by a peer-group externality, which influences neighborhood formation and school choice. Ability-based peer effects in the classroom are confirmed by numerous studies, but this is not without controversy. ${ }^{12}$ This aspect of the model can be given a more generic interpretation. Any household variable that positively affects both the performance of the child and the child's school conforms to the model. ${ }^{13}$ Parental input in the education process that entails both helping the child and the school is an example. Parental input in the school might come in the form of direct participation in education (e.g., classroom volunteer work) or in monitoring and disciplining teachers and administrators. ${ }^{14}$ McMillan (2000) provides evidence of positive parental effects on school quality operating through parent-teacher associations with parental involvement predicted by income and educational level. For all these interpretations of household characteristic $b$, it is likely to be positively correlated with parental educational attainment, hence also with household income. We show when and why positive correlation between $b$ and $y$ is important. We will continue to refer to $b$ as student ability for expositional ease. ${ }^{15}$

12. The influence of ability on own educational achievement is well documented and not controversial (see Hanushek 1986). In the economics literature, Henderson, Mieszkowski, and Sauvageau (1978); Summers and Wolfe (1977); Toma (1996); Zimmer and Toma (1999); Sacerdote (2000); and Hoxby (2000b) find significant peer group effects. Evans, Oates, and Schwab (1992) adjust for selection bias in the formation of peer groups and show that it eliminates the significance of the peer group in explaining teenage pregnancy and dropping out of school. They are careful to point out that their results should not be interpreted as suggesting that peer group effects do not exist, but that scientific demonstration of those effects is inadequate. Note, too, that their work supports the notion that peer group variables enter the utility function, because a selection process does take place. See also Cullen, Jacob, and Levitt (2000). The psychology literature on peer group effects in education also contains some controversy. See Moreland and Levine (1992) for a survey that concludes: "The fact that good students benefit from ability grouping, whereas poor students are harmed by it, suggests that the mean level of ability among classmates, as well as variability in their ability levels, could be an important factor. The results from several recent studies . . . support this notion."

Theoretical models of education that incorporate peer group effects include Arnott and Rowse (1987); Manski (1992); Eden (1992); Rothschild and White (1995); Epple, Newlon, and Romano (2002); Epple and Romano (1998, 1999); and Caucutt (2002), in addition to the papers discussed in section 7.2.

13. In fact, many of the results are independent of $b$ 's positive impact on the child's own achievement. This is so when the assumption in equation (3), presented below, holds.

14. The monitoring interpretation of the public school input suggests that teacheradministrator contracts should reflect school quality. This interpretation of our model embraces the belief that in fact users of a school are the primary enforcers of (implicit) contracts, and they vary in their ability and willingness to enforce them. McMillan (1999) develops a related theoretical model. For a study of the effects of centralized versus decentralized school finance systems on the effectiveness of explicit incentive contracts with school administrators, see Hoxby (1995).

15. We should also note that measuring the peer quality with the mean of $b$ in the school is less restrictive than it may appear. Relevant to the student ability interpretation, some researchers have argued that reduced variation in ability in the classroom facilitates curriculum specialization, thus improving the quality of instruction. Our model and qualitative results generalize to measuring peer quality as the mean in the school of any increasing function $h(b)$ 
That housing prices serve as screens to accessing neighborhoods is not controversial (see Black 1999 and Barrow 1999). We think it is important to introduce housing markets into the model, but have adopted a simple specification. We examine income taxation rather than property taxation so that tax liabilities rise continuously with income. The model can be varied to examine property taxation, with results that are qualitatively the same.

\subsection{School Policy and Equilibrium}

\subsubsection{Equilibrium with Neighborhood Schooling}

This model applies whenever the political jurisdiction encompasses multiple neighborhoods, each providing schooling for its own residents, if household entry into and exit from the jurisdiction can reasonably be ignored. This analysis also provides a basis for investigating cases with multiple districts consisting of multiple neighborhoods, as we discuss in the concluding section. Toward developing the properties of equilibrium, note first that here the school choice stage is trivial, committed in the initial residential choice stage. Providing conditions for and describing a voting equilibrium are not problematic except for one minor issue. We must guarantee that equilibrium permits everyone to purchase a house. Later we explicitly address this issue and develop voting equilibrium properties for the case of Cobb-Douglas preferences (equation [1]). For now, take as given the existence of a unique voting equilibrium in the third stage, with everyone able to afford a house. By definition, centralized finance implies a single tax rate and $X_{1}=X_{2}=\ldots=X_{N}$, where, here and henceforth, subscripts indicate the neighborhood.

We focus now on the residential choices. Although the voting equilibrium depends on the residential allocation, it is not influenced by individual (atomistic) household choice, implying that households treat the anticipated voting outcome as a given in the residential-choice stage. Our primary concern is with the nature of equilibria having differentiated neighborhoods, school peer groups, and school qualities. An issue relevant to the equilibrium allocation of households about which there is little evidence is how student ability affects the demand for school quality. We restrict consideration to two possibilities:

$$
\frac{U_{q}}{U_{y}} \text { is invariant to ability; }
$$

of ability (i.e., $\theta=E h[b]$ in the school). If $h(b)$ is concave, for example, then decreases in Rothschilde-Stiglitz variability of student ability increase peer quality, accommodating the curriculum-specialization hypothesis. See Epple, Newlon, and Romano (2002) and Epple and Romano (1999) for more detail about this generalization of the model. For expositional ease, we present the results here using the simple mean of $b$. 


$$
\frac{U_{q}}{U_{y}} \text { increases with ability. }
$$

In the latter case, the demand for school quality is normal in student ability. The case in equation (3) is neutral on this issue and is a property of the Cobb-Douglas specification.

The first proposition describes some necessary properties of any equilibrium with differentiated schools or neighborhoods.

Proposition 1. For $K \leq N$, suppose $q_{1}<q_{2}<\ldots<q_{K}$. (If $K<N$, then some neighborhoods have schools of the same quality.) Then the following will occur: (a) Housing prices ascend: $p_{1}<p_{2}<\ldots<p_{K}$. (b) The allocation exhibits income stratification: If household with income $y_{1}$ chooses neighborhood having school quality $q_{i}$ and household with child of the same ability but income $y_{2}$ necessarily chooses neighborhood having higher school quality $q_{i}(j$ $>i)$, then $y_{2}>y_{1}$. (c) If assumption (4) holds, the allocation exhibits ability stratification analogously defined. ${ }^{16}$ Under equation (3), household residential choice is invariant to the student's ability. (d) The allocation exhibits boundary indifference and strict preference within boundaries: Type space (the $[b, y]$ plane) is partitioned into neighborhoods by (measure zero) boundaries along which the corresponding households are indifferent to adjacent neighborhoods, and for which interior households have strict preference for their neighborhood over differentiated neighborhoods.

Proof. Since everyone pays the same tax rate, part (a) follows simply. Housing price must be lower if school quality is lower to attract any residents. Given part (a), the converse of part (b) contradicts equation (1). Part (c) is proved analogously. Part (d) is implied by continuity of $U(\cdot)$.

Figure 7.3 illustrates a potential equilibrium allocation for a case with $K$ $=N=3$ and assuming equation (3). Stratification by income arises but not by ability, households with incomes $y_{1}\left(y_{2}\right)$ are indifferent to residing in neighborhoods 1 or 2 (2 or 3 ), and all other households strictly prefer their neighborhood of residence. For preferences instead satisfying equation (4), the boundary loci in type space separating differentiated neighborhoods are downward sloping, exhibiting stratification by both ability and income.

The next proposition establishes conditions for existence of equilibrium with differentiated neighborhoods and schools (continuing to take as given existence and uniqueness of voting equilibrium).

Proposition 2. (a) Equilibrium with differentiated schools exists if preferences satisfy equation (3) and $E[b \mid y]$ is increasing in $y$. (b) Equilibrium with differentiated schools sometimes exists if preferences satisfy equation (4) and

16. For any given income, only higher-ability students attend higher-quality schools. 


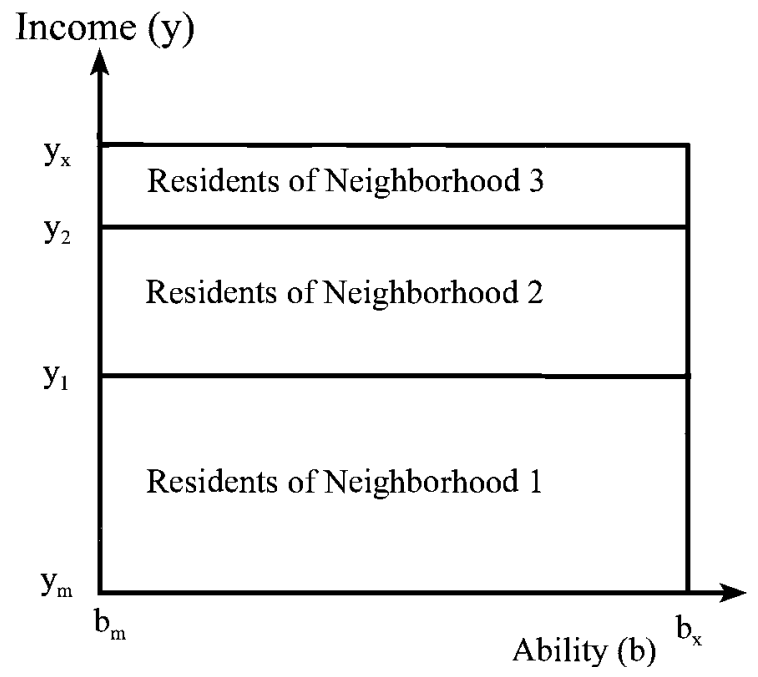

Fig. 7.3 Residences and peer groups in neighborhood equilibrium

either $E[b \mid y]$ is increasing in y or constant. (c) Constancy of $E[b \mid y]$ and preferences satisfying equation (3) are inconsistent with existence of equilibrium having differentiated schools.

Proof. We show part (a) in the appendix by construction (see the proof of proposition A1). We have worked out examples demonstrating part (b), which are available on request. Regarding part (c), under equation (3), proposition 1 shows that an equilibrium with differentiated schools must exhibit stratification by income but not by ability (e.g., as in figure 7.3). However, constancy of $E[b \mid y]$ then implies equal $\theta$ s in all schools, hence schools of equivalent quality - a contradiction.

School qualities can vary due only to variation in peer groups because expenditures are equalized across neighborhoods. Access to neighborhoods with better peer groups is rationed by higher housing prices. This rationing must be consistent with differentiated peer groups for such an equilibrium. If willingness to pay for school quality depends only on income (i.e., under equation [3]), then stratification across neighborhoods will be determined solely by income, as in figure 7.3. Income and ability must then be positively correlated to produce the school quality hierarchy. The mean ability or peer-group measure in any neighborhood $i(i=1,2, \ldots, N)$ can be written thus:

$$
\theta_{i} \equiv \frac{\int_{y_{i-1}}^{y_{i}} \int_{b_{m}}^{b_{x}} b f(b, y) d b d y}{\int_{y_{i-1}}^{y_{i}} \int_{b_{m}}^{b_{x}} f(b, y) d b d y}=\frac{\int_{y_{i-1}}^{y_{i}} E[b \mid y] \cdot\left[\int_{b_{m}}^{b_{x}} f(b, y) d b\right] d y}{\int_{y_{i-1}}^{y_{i}} \int_{b_{m}}^{b_{x}} f(b, y) d b d y}
$$


where $y_{i-1}$ is the minimum income type of household residing in neighborhood $i$ and $y_{i}$ is the maximum. Hence, given that $E[b \mid y]$ is increasing in $y$, the income stratification implies school quality stratification.

Alternatively, if willingness to pay for school quality also increases with the child's ability (i.e., under equation [4]), then positive correlation between ability and income is unnecessary for a differentiated equilibrium. In these equilibria, the $(b, y)$ plane is partitioned into neighborhoods by downward-sloping boundary loci, with relatively high-income and low-ability households mixing with relatively low-income and high-ability households. Although the existence of equilibrium with differentiated neighborhoods cannot generally be shown under equation (4), we have consistently found such equilibria in simulations of specific cases.

In all that follows (and without constant repetition), we adopt the assumption in equation (3) and thus also assume that $E[b \mid y]$ is increasing in $y$. With $N$ neighborhoods, equilibrium can have $N$ different neighborhood peer groups and school qualities. In fact, proposition A1 in the appendix shows that a multiplicity of such equilibria exists if neighborhoods differ in size. We henceforth assume that school administrators choose neighborhood boundaries so that schools are of the same size, thus eliminating this multiplicity. This is a natural simplifying assumption because differentiated equilibria arise whether or not schools are of equal size, and no new issues arise in extending the results to schools of unequal size. We also anchor the housing price in the poorest neighborhood at $c$, as must arise in the variation of the model with elastic housing supply in one neighborhood, eliminating a degree of freedom in housing prices that arises otherwise. Other equilibria exist as well, with subsets of neighborhoods having the same peer groups, school qualities, and housing prices, including the allocation with no neighborhood differentiation. Such equilibria are unstable under reasonable adjustment assumptions. ${ }^{17}$ This instability and the empirical evidence (see below), including evidence on school-driven housing price dif-

17. The argument that an equilibrium that is not maximally stratified will tend to be unstable is as follows. An arbitrary finite perturbation of the residences across neighborhoods beginning with $\theta_{1}=\theta_{2}$ would generally imply differences in the peer measures. Households would relocate toward the higher-quality neighborhood and bid up its relative housing price, implying that the relocation pattern would satisfy income stratification (as in proposition 1[b]). In turn, the relocations and the assumption in equation (1) would imply greater quality differential, and so on. To formalize this argument, one needs to make assumptions about the rates at which types relocate and what they anticipate would change, if anything. Consider an example. Suppose that there are two neighborhoods, initially homogeneous with $p_{1}=p_{2}=c$. Perturb their residences so that $\theta_{2}$ is a little higher than $\theta_{1}$. Now let an arbitrarily selected positive measure of types relocate and suppose that they anticipate no changes in variables due to their own relocations. The housing market price that clears their housing exchanges must have $p_{2}>p_{1}$ (the latter price might be anchored at $c$ ), and the relocation pattern must satisfy income stratification among those moving. However, then $\theta_{2}$ would rise further and $\theta_{1}$ would decline further, these implied by equation (1) and the assumption that the measure permitted to move was selected arbitrarily (i.e., the $\theta$ s would change as stated with probability one). 
ferentials within jurisdictions (Black 1999; Barrow 1999), lead us to ignore such equilibria.

Hence, we study the equilibrium with each neighborhood having a differentiated school and with a housing price of $c$ in the poorest neighborhood. We emphasize that all stable equilibria in our model, whether or not schools are of equal size, have every neighborhood school differentiated.

Central cities in the United States are typically served by a single school district, as is assumed in our model, and provide evidence supporting our predictions. Income stratification across central-city neighborhood schools of the form we have described is quite evident in cities. Data from high schools in the city school district of Los Angeles (i.e., the Los Angeles Unified District) provide an illustration of the extent of income stratification. Although direct measures of household income by school are unavailable, data are available on the percentage of students in each school who are from low-income households - children who qualify for free or reduced-price lunch.

In panel A of figure 7.4 we plot the percentage of low-income students in each of the fifty-five "regular" high schools in the city of Los Angeles for the 1997-98 school year. We exclude schools classified in the Common Core of Data as "special educational" or "alternative," mainly because they frequently have much smaller enrollments, although their inclusion would not alter the message. In this plot, schools are ordered by their percentage of low-income students. This figure reveals that there is substantial income stratification. As a benchmark for comparison, consider random assignment of students to schools. We also show in panel A of figure 7.4 the 95 percent confidence bounds for the mean number of low-income students per school under random assignment of this population of students to schools. ${ }^{18}$ The narrowness of these bounds stands in dramatic contrast to the observed variation across schools, confirming that there is a high degree of income stratification across neighborhood schools. In addition to peer effects in schools, there is no doubt that other factors support the observed stratification. These include incentives to interact regularly with others of similar background (educational, socioeconomic, and racial), incentives to locate near employment, and a durable and somewhat stratified existing housing stock. Our analysis of neighborhood equilibria attributes all stratification to school-based peer effects, which is clearly an exaggeration.

Research on local jurisdictions, following Tiebout, has traditionally emphasized sorting across rather than within jurisdictions. Most of the high schools in the other 110 districts in metropolitan Los Angeles have just one or a few high schools. In 1997-98, 41 percent of these districts had one (reg-

18. We use the normal approximation to the binomial distribution in calculating these confidence bounds, which is quite accurate given that the smallest school has 212 students and all but three schools have over 1,000 students. The fluctuation in the boundaries reflects differences in the sizes of the schools. 

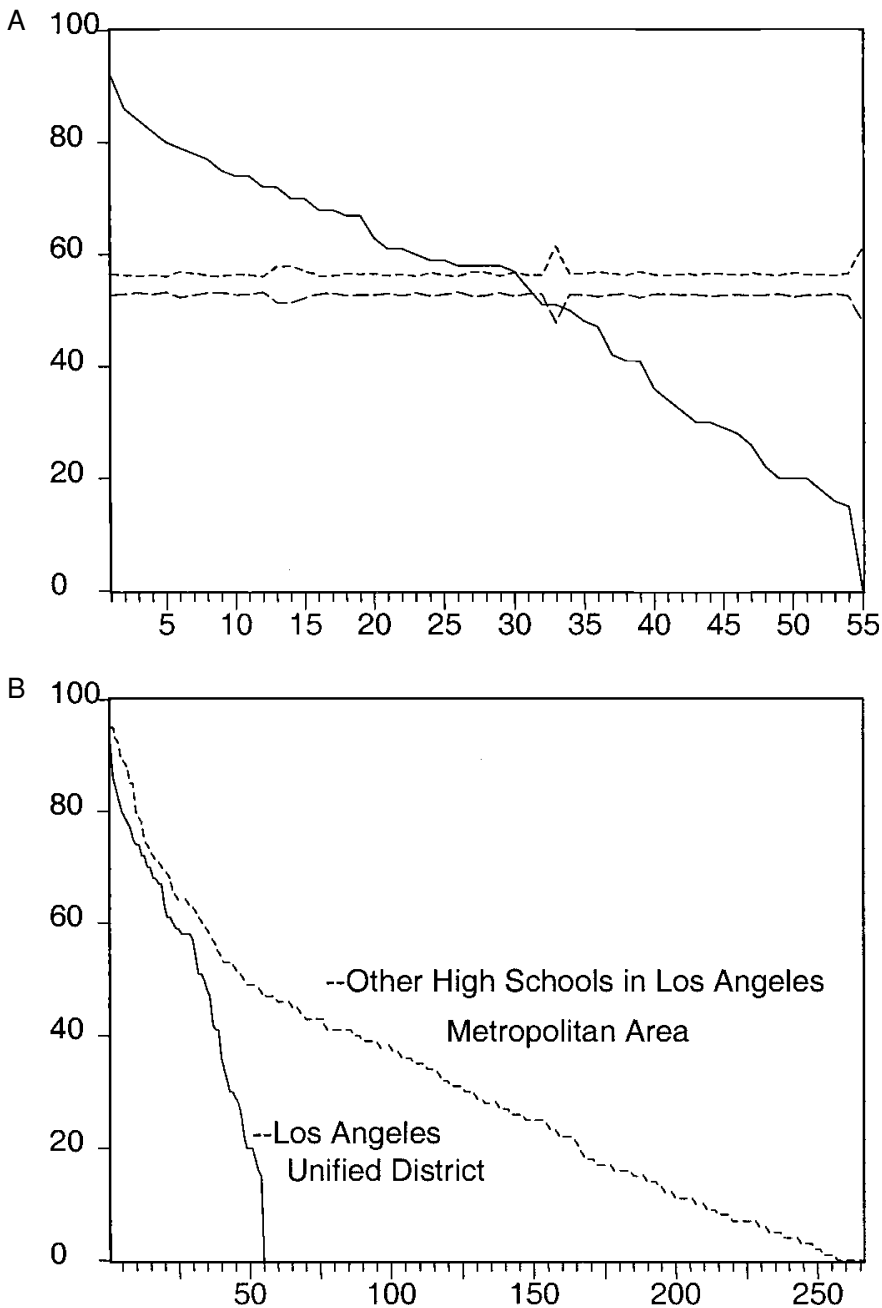

Fig. 7.4 $A$, Percent low-income students and 95 percent confidence bounds for high schools in Los Angeles unified district; $B$, percent low-income students in high schools in the Los Angeles metropolitan area

ular) high school, 62 percent had two or less, and 78 percent had three or less. Thus, jurisdictions in suburban Los Angeles accord reasonably well with the kind of structure presumed in most prior research. In light of this, it is of interest to compare stratification patterns between the 53 city high schools and the 266 suburban high schools in the Los Angeles metropolitan area. This is done in panel B of figure 7.4. The solid curve in the plot reproduces panel A of figure 7.4, and the new curve contains the percentage of low-income students for the suburban schools, with these also ordered by 
their percentages of low-income students. There is, as expected, stratification by income between city and suburbs. The mean of the proportion of low-income students in the city schools is 0.525 , whereas it is 0.312 in the suburban schools. Of more interest, however, is the degree of stratification among suburban (Tiebout) schools relative to the degree of stratification among city (neighborhood) schools. Inspection of panel B suggests that the pattern of stratification among the city schools is not dramatically different from that of the suburban schools. The standard deviations of percentage of low-income students in the city and the suburbs are 0.222 and 0.230 , respectively. Although it is not clear what is the right metric for comparing stratification in the two cases, the data for Los Angeles high schools reveal a high degree of income stratification across all schools and point to the need for more extensive investigation of the sorting of households within jurisdictions.

We now discuss voting equilibrium. To obtain precise results, we restrict consideration henceforth to the Cobb-Douglas utility specification (1). ${ }^{19}$ We also set $N=2$ in what follows for simplicity. Hence, the neighborhood housing capacities are $1 / 2$, and we know that the equilibrium partition of households has $y_{1}=y_{\text {med }}$ as the boundary locus, $y_{\text {med }}$ denoting the median income. Number the poorer neighborhood 1 and the wealthier neighborhood 2. Using equation (2) and setting $p_{1}=c$, find $p_{2}$ from the fact that the median-income household is indifferent to residence in equilibrium (proposition $1[\mathrm{~d}])$ :

$$
p_{2}=c+\left[y_{\text {med }}(1-t)-c\right]\left[1-\left(\frac{\theta_{1}}{\theta_{2}}\right)^{\gamma}\right] .
$$

Since the partition implies $\theta_{1}<\theta_{2}$ (and assuming the median-income household can afford a house), inspection of equation (6) confirms that $p_{2}>p_{1}$. We also see that housing prices are independent of per-student expenditure, due to the Cobb-Douglas specification.

One can find voting equilibrium following the methodology used in Epple and Romer (1991). The detailed analysis is in the appendix. Here we summarize the logic and results. Assume for simplicity that only tax rates that allow the poorest type to purchase homes can be adopted: $t \leq\left(y_{m}-c\right)$ / $y_{m} \cdot{ }^{20}$ It turns out that preference for higher-expenditure tax pairs increases with $y / p$. That is, households with a higher ratio of income to housing price favor more educational expenditure, although this requires a higher tax

19. Voting equilibrium can be shown to exist much more generally. See Roberts (1977), Epple and Romer (1991), and Gans and Smart (1996).

20. We have in mind an income policy that precludes equilibrium taxation such that the poorest household cannot afford housing in so restricting feasible taxes. A specific policy that yields this without direct restriction on the tax rate dictates no additional tax liability once a household is driven down to subsistence: Household with income $y$ pays a maximum of $y-c$ in taxes. One can confirm that proposition 3 continues to apply without its tax ceiling under our assumption below that problem (8) has an interior solution. 
rate. The tax rate most preferred by households with median value of $y / p$ is then majority preferred. The latter tax and implied per-student educational expenditure is the equilibrium pair because it would defeat any other feasible pair in a tax referendum.

With one minor technical assumption on the income distribution (see equation [A1] in the appendix), there are median-preference households residing in (the poorer) neighborhood 1 having income denoted $y_{p 1}$ and median-preference households residing in neighborhood 2 having income $y_{p 2}$ $\equiv\left(p_{2} / c\right) y_{p 1}$. Letting $F_{y}$ denote the marginal cumulative density function (c.d.f.) of income, $y_{p 1}$ solves

$$
F_{y}\left(y_{p 1}\right)+\left[F_{y}\left(\frac{p_{2}}{c} y_{p 1}\right)-0.5\right]=0.5 .
$$

We have the following proposition:

Proposition 3. The solution to

$$
\begin{aligned}
& \max _{t, X}\left[y_{p 1}(1-t)-c\right] X^{\alpha} \\
& \text { s.t. } X=t \bar{y} ; \quad t \leq \frac{y_{m}-c}{y_{m}}
\end{aligned}
$$

is the unique majority voting equilibrium, where $\bar{y}$ denotes the mean income in the population.

The solution to problem (8) is

$$
t^{*}=\frac{\alpha}{1+\alpha}\left(1-\frac{c}{y_{p 1}}\right) \text { and } X^{*}=\frac{\alpha}{1+\alpha}\left(1-\frac{c}{y_{p 1}}\right) \bar{y},
$$

provided it is not on the upper bound of $t$, which is easily ruled out. ${ }^{21} \mathrm{Com}-$ parison to other policy outcomes and numerical examples are provided below.

To summarize to this point, for Cobb-Douglas preferences, $E[b \mid y]$ increasing in $y$, and two neighborhoods of equal size, equilibrium splits households by income at the median into the two neighborhoods, with the wealthy neighborhood having higher $\theta$ (equation [5]). With $p_{1}=c$, the remaining equilibrium variables are described by equations (6), (7), and (9). In addition to the pivotal voters in neighborhood 1 , those with income $p_{2} y_{p 1} / c$, who reside in neighborhood 2 , also have median voting preferences.

Equilibrium is characterized by income stratification across neighborhoods, with differences in school quality deriving from differences in peer groups. More neighborhoods would increase stratification and the spread of schools' peer qualities. Although stratification affects expenditure levels

21. This requires $\alpha\left(1-c / y_{p 1}\right) /(1+\alpha)<\left(y_{m}-c\right) / y_{m}$. One set of sufficient conditions is $\alpha<1$ and $y_{m}>2 c$. 
(as will be discussed further), differences in school qualities obviously have nothing to do with expenditures. All that is needed is that a positive externality in schooling is correlated with household income. The preponderance of research concerning differences in quality of public schools emphasizes expenditure differences. However, equalization of finance will not itself create equal-quality schools. The emphasis on expenditure in most of the literature as well as in policy reform misses a crucial element of the equilibrium determination of schooling quality. The concern for the implications of peer-group effects in schooling is further heightened by the evidence indicating that expenditure per se matters little (e.g., see Hanushek 1986). We return to this discussion after clarifying the implications of alternative policies and welfare effects.

\subsubsection{Equilibrium with School Choice}

The analysis of school choice with no frictions is straightforward. Households select schools without constraint in the second stage of figure 7.2. We assume schools face no capacity constraints and must admit all comers. ${ }^{22}$ School finance continues to entail an allocation of funds to schools so as to equalize expenditure per student. Those who send their child to school in the "other neighborhood" bear no transportation or other transactions costs (introduced later). ${ }^{23}$ Lacking evidence on productivity effects of intradistrict choice, we hold fixed the schooling production function $q(\cdot)$.

The immediate implication is that the exercise of school choice must lead to equal school qualities in equilibrium, and, since expenditures are equalized, $\theta_{1}=\theta_{2}$. Further, indifference to residence is implied, so that $p_{2}=p_{1}(=$ $c)$. Voting equilibrium continues to reflect the preference of a household with median ratio of income to housing price. Because housing prices do not vary, only one type of household has median preference: those families with median income (who can live in either neighborhood). The solution to equation (9) substituting $y_{\text {med }}$ for $y_{p 1}$ is the outcome of the voting equilibrium. ${ }^{24}$ We have established the following proposition:

Proposition 4. Equilibrium values with frictionless choice are given by

$$
\text { (10) } p_{1}=p_{2}=c ; \quad \theta_{1}=\theta_{2}=\bar{\theta} ; \quad \text { and } \quad X_{1}=X_{2}=\frac{\alpha}{1+\alpha}\left(1-\frac{c}{y_{\text {med }}}\right) \bar{y} \text {, }
$$

where $\bar{\theta}$ denotes the mean ability in the entire population. Households with median income are pivotal in the voting equilibrium. The residential allocation

22. The same results obtain if there are capacity constraints, but every applicant, independent of residence, has the same probability of admittance. Aggregate uncertainties disappear because of the atomism of households.

23. We also ignore any possible changes in transportation costs borne by taxpayers. Explicit consideration of transportation costs borne by taxpayers would not effect the set of equilibrium residential and school choices, since these costs are invariant to individual choices.

24 . The parameter restrictions provided in footnote 21 continue to be sufficient. 
is indeterminate. Any allocation assigning half the population to each neighborhood is an equilibrium. Any set of school choices resulting in $\theta_{1}=\theta_{2}$ is an equilibrium set.

Comparing equilibria, introduction of (frictionless) school choice leads to higher $\theta_{1}$ and lower $\theta_{2}$. Using equations (9) and (10) and that $y_{\operatorname{med}}>y_{p 1}$, the tax rate and expenditure are higher under choice. This is explained by an income effect on voting from a lower $p_{2}$. The strongest implication is that households with income below the median attend better schools unambiguously. Further normative and quantitative analysis is in section 7.5.

\section{Interneighborhood Transportation Costs}

We now introduce friction in the exercise of school choice. We assume that it costs any household $T$ to send its child to school in the other neighborhood. Hence, for example, intraneighborhood transportation is costless (or provided), but households bear a private cost of $T$ to transport their children between neighborhoods as across a "Hoxby river" (Hoxby 2000a).

Transportation costs effectively prohibit the exercise of choice if $T$ exceeds the housing price differential that arises without choice. Here equilibrium is as though choice is not allowed. Letting $p_{2}^{*}$ denote neighborhood 2 's housing price in the equilibrium without choice, we then suppose

$$
T<p_{2}^{*}-c,
$$

which is clearly the more realistic case.

We describe an "interior equilibrium," one in which some but not all households exercise choice. Figure 7.5 depicts an interior equilibrium allocation. ${ }^{25} \mathrm{~A}$ threshold income below the median, $y_{1}$, divides households according to the neighborhood where their children attend school. Those with income below $y_{1}$ live in neighborhood 1 , and their children attend school there. Those with higher income send their children to the better school in neighborhood 2 but are indifferent to their neighborhood of residence. A number of households equal to one-half the population drawn from the latter group must live in neighborhood 2 for housing-market clearance. Their residential indifference is supported by a housing price differential equal to the transportation cost:

$$
p_{2}-c=T .
$$

Living in neighborhood 1 and paying the transportation cost is equivalent to avoiding it but paying the higher housing price in neighborhood 2 .

25. Cullen, Jacob, and Levitt (2000) provide evidence of sorting due to public school choice among high schools in Chicago that is consistent with the equilibrium we describe. When instrumenting for peer groups to correct for potential endogeneities they fail, however, to find evidence of peer effects on graduation rates. 
Income (y)

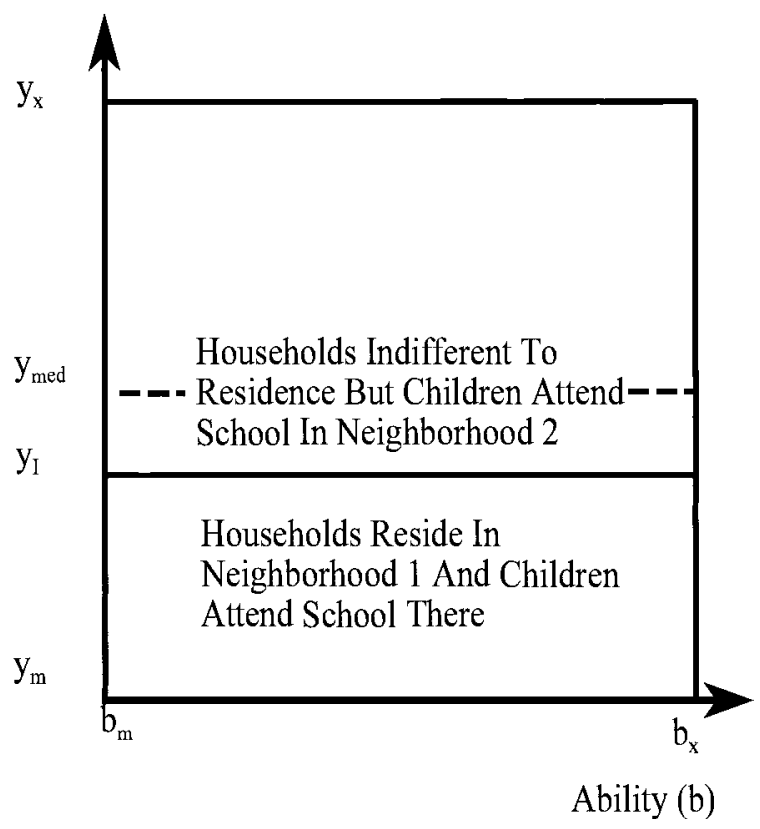

Fig. 7.5 Residences and peer groups with public-school choice and transport cost

Let $\theta_{i}^{*}\left(y_{I}\right), i=1,2$, denote the implied mean ability in neighborhood $i$. Since $E[b \mid y]$ is increasing, $\theta_{2}^{*}>\theta_{1}^{*}$ for all $y_{I}$, although housing-market clearance requires $y_{I}<y_{\text {med }}$. Indifference to transporting one's child from neighborhood 1 to 2 for schooling identifies $y_{I}$ :

$$
T=\left[y_{I}(1-t)-c\right]\left[1-R\left(y_{I}\right)^{\gamma}\right],
$$

where $R\left(y_{I}\right) \equiv \theta_{1}^{*} / \theta_{2}^{*}$.

Voting equilibrium can be determined analogously to the previous models with $T+c$ replacing the housing price for those who live in neighborhood 1 and transport their child to school in neighborhood 2. All those with $y>y_{I}$ pay "effective housing price" equal to $p_{2}$. There is always a median preference voter with $y>y_{I}$, whose income we denote $y_{p 2}$ (and there may or may not be one having $y<y_{I}$ ). By ordering households according to their income divided by effective housing price, one can identify $y_{p 2}$ as detailed in the appendix. Replacing $y_{p 1}$ with $y_{p 2}$ in equation (9), we compute ${ }^{26}$

$$
t=\frac{\alpha}{1+\alpha}\left(1-\frac{p_{2}}{y_{p 2}}\right) ; \quad \text { and } \quad X=t \bar{y} .
$$

26. The parameter restrictions in footnote 21 remain sufficient. 
Proposition 5. Assume equation (11) is satisfied and any voting equilibrium permits everyone to afford housing. A solution $\left(p_{2}, y_{I}, t, y_{p 2}, X\right)$ with $y_{I}<$ $y_{\text {med }}$ to equations (12) through (14), with $y_{p 2}$ as calculated in the appendix, and with $\theta_{i}=\theta_{i}^{*}\left(y_{I}\right), i=1,2$, is an interior equilibrium with allocation depicted in figure 7.5 (and with any mass equal to one-half of households having $y>y_{I}$ living in neighborhood 2).

Although existence and uniqueness of an interior equilibrium are not guaranteed, we find unique interior equilibrium for a range of $T$ in our computational model of section 7.5. Another possibility is a "boundary equilibrium" having $p_{2}=T+c$, but where everyone attends school in neighborhood 2 . Here $T$ is low enough that choice induces everyone to get the same schooling.

Relative to the no-choice equilibrium, the exercise of choice by those with below-median income is on average associated with a negative peer-group externality to both those who stay behind and attend school in neighborhood 1 , and to those with above-median income. Both $\theta_{1}$ and $\theta_{2}$ decline because $E[b \mid y]$ is an increasing function of $y$. The decline in neighborhood 1 , borne by the poorest segment of the population, supports the concerns of some critics of choice: Those least equipped to exercise choice suffer from its introduction. Because the outcome of the voting equilibrium changes, we must quantify effects to pursue further normative analysis, which is taken up later in section 7.5.

\subsubsection{Multiple Jurisdictions: Tiebout Equilibrium}

It is of interest to compare the single-district equilibria above to the more decentralized provision regime, in which education finance is highly localized. Here the two neighborhoods are assumed to correspond to two political jurisdictions for the determination of the tax rate and per-student expenditure. Policy dictates that households' children must attend school in their neighborhood-district of residence. Otherwise, we maintain the properties of the model including Cobb-Douglas preferences (hence equation [3]), the same housing capacities of $1 / 2$ in each now-jurisdiction, and $E[b \mid y]$ increasing in $y$. As in the single-district model without choice, the schoolchoice stage is trivial because, again, school is dictated by residence. This version of our model is akin to an environment with small school districts that is fairly densely populated as in areas of Pennsylvania, New Hampshire, Ohio, and Vermont, for example. ${ }^{27}$

We focus again on equilibrium with differentiated schools for the same reasons as above. First, we have the following proposition:

27. The 1993-94 respective ratios of high schools to districts in these states were 1.20, 1.03, 1.27 , and 1.02 (U.S. Department of Education 1994). 
Proposition 6. Any equilibrium with differentiated schools exhibits the following: (a) stratification by income (independent of ability); and (b) boundary indifference and strict preference within boundaries.

Proof. Using equation (2), calculate the sign of the utility difference $(\Delta)$ from residing in neighborhood 2 versus 1 : $\operatorname{sgn} \Delta=\operatorname{sgn}\left\{\left[\left(1-t_{2}\right) q_{2}-(1-\right.\right.$ $\left.\left.\left.t_{1}\right) q_{1}\right] y+\left(p_{1} q_{1}-p_{2} q_{2}\right)\right\}$. Housing market clearance implies that one-half the population lives in each neighborhood. Linearity of $\Delta$ in y then implies either income stratification (that is independent of ability) and differentiated schools or that $\Delta$ vanishes for every income. The latter case is an unstable equilibrium having everyone indifferent. Given that $\Delta$ does not vanish for some $y$, boundary indifference for $y=y_{\text {med }}$ and strict preference otherwise are then implied by the linearity.

Residential choices and peer groups are then the same as in the singlejurisdiction model without choice. Each neighborhood or jurisdiction chooses its own tax rate, however. Households within a neighborhood face the same housing price, and voting equilibrium is calculated as above. The households with median preferences in neighborhoods 1 and 2 have firstquartile income $\left(y_{q 1}\right)$ and third-quartile income $\left(y_{q 3}\right)$, respectively. The voter's problems are analogous to equation (8) with the obvious substitutions: ${ }^{28}$

$$
\begin{gathered}
t_{1}=\frac{\alpha}{1+\alpha}\left(1-\frac{p_{1}}{y_{q 1}}\right) ; \quad X_{1}=t_{1} \bar{y}_{1} ; \\
t_{2}=\frac{\alpha}{1+1}\left(1-\frac{p_{2}}{y_{q 3}}\right) ; \quad \text { and } \quad X_{2}=t_{2} \bar{y}_{2},
\end{gathered}
$$

where $\bar{y}_{i}, i=1,2$, denotes mean income in neighborhood $i$. Note that it not immediately clear where tax rates are higher and where per student expenditure is higher. Boundary indifference implies that prices satisfy

$$
\left[y_{\text {med }}\left(1-t_{2}\right)-p_{2}\right] q_{2}=\left[y_{\text {med }}\left(1-t_{1}\right)-p_{1}\right] q_{1},
$$

which allows us to demonstrate the following:

Proposition 7. $q_{2}>q_{1}$ in equilibrium.

Proof. If $p_{2} \leq p_{1}$, then $t_{2}>t_{1}$ and $X_{2}>X_{1}$, both by equations (15) and (16). The better peer group in neighborhood 2 then implies the result. For the case of $p_{1}<p_{2}$, suppose to the contrary that $q_{2} \leq q_{1}$. From equation (17), then, $\left[y_{\text {med }}\left(1-t_{2}\right)-p_{2}\right] \geq\left[y_{\text {med }}\left(1-t_{1}\right)-p_{1}\right]$, implying $p_{2}-p_{1} \leq\left(t_{1}-t_{2}\right) y_{\text {med }}$. Substitute from equations (15) and (16) for the ts in the latter, yielding

$$
p_{2}-p_{1} \leq=\frac{\alpha}{1+\alpha}\left(p_{2} \frac{y_{\mathrm{med}}}{y_{q 3}}-p_{1} \frac{y_{\mathrm{med}}}{y_{q 1}}\right) \text {. }
$$

28. Again we assume that $t$ is not at its upper bound, and again the conditions in footnote 21 continue to be sufficient, assuming $p_{1}=c$. 
Since $\alpha /(1+\alpha)<1$ and $y_{q 3}>y_{\text {med }}>y_{q 1}$, equation (18) contradicts $p_{2}>p_{1}$.

Proposition A2 in the appendix provides conditions for existence of differentiated equilibrium. These conditions also imply that the housing price will be lower in the poorer district, hence $p_{1}=c$. They are satisfied in realistic cases, including our computational analysis in the next section.

Relative to the single-jurisdiction, multineighborhood environment without choice, one would expect here lower per-student expenditure in the poor neighborhood-district and the opposite in the wealthy neighborhooddistrict due to the changes in the tax base. A wider dispersion in school quality under multiple jurisdictions is then implied. The theoretical analysis is, however, obscured by changes across the equilibria in the identities of the pivotal voters and housing prices. We explore this issue computationally in section 7.5.

For our Cobb-Douglas specification with fixed housing capacities, residential choices and thus peer groups are exactly the same, with no school choice whether or not neighborhoods are also political jurisdictions. This illustrates a central result of this paper: Peer-group effects alone can lead to income-stratified equilibrium and school quality differences, as in a Tiebout equilibrium with local public finance. ${ }^{29}$ If we depart from a Cobb-Douglas specification or assume upward-sloping housing supplies, then the residential allocation will vary somewhat across the two regimes. However, this is only to the extent that educational expenditure is important to school quality. In the Cobb-Douglas case with upward-sloping housing supplies, for example, the allocations converge as $\alpha \rightarrow 0$. If educational expenditure has small effects at the margin, as most evidence indicates (see Hanushek 1986, 1997 and Betts 1996), then policies that more evenly distribute educational funds will not much reduce stratification absent school choice. ${ }^{30}$

Interjurisdictional school choice is also worthy of study. ${ }^{31}$ The analysis of interjurisdictional school choice depends on how the choice policy implements school finance when choice is exercised. Here we briefly summarize some results, because space constraints prevent a complete presentation. In an early version of this paper (Epple and Romano 1995), we analyzed frictionless interjurisdictional choice assuming that those who cross district boundaries bring with them their own jurisdiction's locally determined perstudent expenditure. This policy leads to a nonstratified outcome and ho-

29. As discussed in section 7.2, an alternative version of this result can be found in Benabou (1993, 1996).

30. It is correct to observe that even for small $\alpha$ in the Cobb-Douglas case, stratification may result with multiple jurisdictions if $E[b \mid y]$ is invariant to $y$, and equilibrium will not be stratified in the single-jurisdiction model. Note, however, that only slightly rising $E[b \mid y]$ gets back stratification in the latter model. Moreover, for utility specifications satisfying equation (4) and $E[b \mid y]$ flat, near equivalence holds as expenditure effects disappear.

31. In 1993-94, 28.6 percent of school districts had interdistrict choice policies (U.S. Department of Education 1996). However, only 1.6 percent of public school students residing in these districts attended school outside of the district where they resided. 
mogeneous schools, but with a severe free-rider problem in school finance: Voting to raise one's local tax would attract outsiders (or reduce exit), and this externality would lead to substantially lower schooling expenditure. Anticipating this, an interjurisdictional choice policy might require that a household exercising choice become a member of its chosen school's jurisdiction for purposes of school finance. That is, it pays its chosen district's tax rate while being allowed to vote there on the school budget. ${ }^{32}$ We show in the appendix that this policy would frequently lead to the same outcome as does choice in a single jurisdiction if there are no frictions (i.e., nontax costs) to exercising choice. The logic is that housing prices must be equalized in equilibrium, and potential differences in tax rates will frequently not alone be enough to support an outcome with stratified schools. However, as we discuss more fully below, potential recipient districts generally have an incentive to resist accepting students from outside the district, casting doubt on the extent to which choice is likely to be frictionless.

\subsection{Computational Analysis and Welfare Effects}

We begin with a general discussion of welfare issues that will facilitate the interpretation of the computational results that follow. Although much of our analysis concerns traditional efficiency measures, this is presented with serious caveats. First, education is regarded by many as a primary means to lessen equity problems, and we are not unsympathetic to this view. Second, equity aside, long-term social externalities associated with low educational achievement or wide variance in educational achievement may exist (e.g., crime and resentment). For both these reasons, it is important to also consider the distribution of educational achievement.

A third caveat concerns education as an investment rather than a consumption good. If education is an investment good, then our model implicitly assumes imperfect opportunities for borrowing on future earnings, which constrains all households. This follows from our assumption that household demand for educational quality increases with income. ${ }^{33}$ Such credit constraints are also consistent with Peterson et al.'s findings (chap. 4 in this volume) that small partial vouchers are needed to induce poor families to switch to private schools in spite of relatively large educational gains. The standard static analysis does not properly measure welfare changes under the investment interpretation; one must measure and value changes in aggregate achievement and factor this into the welfare measure. Our belief is that education has both investment and consumption value.

32. Whether outsiders are allowed to vote or not does not matter to equilibrium.

33. Actually, our equilibrium results do not require a binding borrowing constraint on highincome households, specifically those with income above the maximum income of any pivotal voter. If demand ceases to increase with income above this threshold, all our equilibrium results continue to hold. 
With these reservations in mind, we turn to standard efficiency analysis. Understanding properties of Pareto efficient (PE) allocations provides perspective for understanding the variation in welfare (producer surplus plus compensating variation) across the policy regimes analyzed below. In examining PE allocations, we assume that there are at most two schools and that an allocation entails an assignment of all students to a school (i.e., no schooling is not an option). Let $A_{i}(b, y) \in[0,1]$ denote the proportion of students of type $(b, y)$ attending school $i, i=1,2$, so that $A_{1}(b, y)+A_{2}(b, y)$ $=1$ for all $(b, y)$. For the applications we study, $A_{i}$ will equal 0 or 1 for all types: That is, efficient student bodies entail no overlap of types. We assume no transportation costs so that neighborhood residence is irrelevant to efficiency. Set $p_{i}=c, i=1,2$, giving the anonymous land owners no rents. Proposition 8 is the main result in Epple and Romano (2000). It includes a description of the "social marginal cost" of a student attending school $i$, which we denote $\mathrm{SMC}_{i}$. Also, let $r_{i}(b, y)$ denote the "regulated price" that a social planner charges type $(b, y)$ to attend school $i$. Actually, $r_{i}(b, y)$ will turn out to be a function only of $b$ at the optimum as we will see.

Proposition 8 is a variant of the Second Fundamental Welfare Theorem in economics.

PROPOSITION 8. If appropriate lump-sum transfers of income are arranged, then every $P E$ allocation can be achieved by utility-maximizing school choices, with, for all $(b, y)$, students paying prices

$$
r_{i}(b, y)=\mathrm{SMC}_{i} \equiv X_{i}+\frac{q_{\theta}\left(X_{i}, \theta_{i}\right)}{q_{X}\left(X_{i}, \theta_{i}\right)}\left(\theta_{i}-b\right), \quad i=1,2,
$$

with $X_{i}$ satisfying

$$
\iint_{s} A_{i}(b, y) \frac{\partial U^{i}(b, y) / X_{i}}{\partial U^{i}(b, y) / \partial y} f(b, y) d b d y=\iint_{s} A_{i}(b, y) f(b, y) d b d y, \quad i=1,2 ;
$$

$$
U^{i}(b, y) \equiv U\left[y-c+R(b, y)-r_{i}(b, y), a\left(q\left(X_{i}, E_{i}\right), b\right], \quad i=1,2\right.
$$

$R(b, y)$ denoting the lump-sum transfer function; and, finally, $\theta_{i}, i=1,2$, and $A_{i}(b, y)$ as implied by utility-maximizing choices.

Proof. See Epple and Romano (2000).

Here we provide only intuition for this result, with formal proof in the paper cited. With prices that reflect the peer externality in schools (and efficiently chosen expenditure levels), individual school choice will yield an efficient allocation. The social cost of type $(b, y)$ entering school $i$ is given by $\mathrm{SMC}_{i}$, which equals the per-student expenditure plus the dollar value of the peer-group externality. The value of the peer externality is the last term in equation (19). $q_{\theta} / q_{X}$ equals the cost of maintaining quality as $\theta$ changes, which is multiplied by $\left(\theta_{i}-b\right)$, the change in $\theta_{i}$ that results due to student type $b$ 's attendance at $i$. Note that the peer-group cost of attendance is neg- 
ative for students having ability higher than the student body's mean $(b>$ $\theta_{i}$ ), and their SMC can then be negative. Note, too, that the social cost depends on $b$, but not $y$. Hence, efficient prices depend on ability but not income.

The efficient expenditure levels satisfy the within-school "Samuelsonian conditions" in equation (20) that equate the sum of marginal values of educational expenditure to marginal expenditure cost. Note that school budgets balance: Integrating $r_{i}$ over the student body in $i$ yields total expenditure in school $i$. The lump-sum transfers that are considered must also satisfy budget balance.

We next consider implications in the case of Cobb-Douglas utility that we have adopted. A natural benchmark allocation presumes no income transfers, so set $R(b, y)=0$ for all $(b, y)$. We have the following proposition:

Proposition 9. For Cobb-Douglas utility/achievement, the no-transfer PE allocation has (a) $q_{2}>q_{1}$; (b) stratification by income with linear boundary locus

$$
y=\left[c+\frac{\left(X_{2}+\eta_{2} \theta_{2}\right) q_{2}-\left(X_{1}+\eta_{1} \theta_{1}\right) q_{1}}{q_{2}-q_{1}}\right]-\left(\frac{\eta_{2} q_{2}-\eta_{1} q_{1}}{q_{2}-q_{1}}\right) b,
$$

where $\eta_{i} \equiv\left(q_{\theta} / q_{X}\right)_{i}, i=1,2$; $(c)$

$$
\begin{gathered}
X_{i}=\frac{\alpha}{1+\alpha}\left(\bar{y}_{i}-c\right), \quad i=1,2 ; \quad \text { and } \\
\eta_{i}=\frac{\gamma}{(1+\alpha)} \frac{\left(\bar{y}_{i}-c\right)}{\theta_{i}}, \quad i=1,2,
\end{gathered}
$$

where $\bar{y}_{i}$ and $\theta_{i}$ are the school means implied by the efficient allocation. Further, $E[b \mid y]$ invariant to $y$ is sufficient for (d) $\theta_{2}>\theta_{1}$; and (e) stratification by ability (hence, a downward-sloping boundary locus). If, also, $\gamma<1$, then (f) $X_{2}>X_{1}$.

Proof. See the appendix.

Figure 7.6 illustrates a typical PE allocation, calculated for the baseline case of our computational model (parameter values match those in table 7.1 , discussed later). It is notable that a strict hierarchy $\left(q_{2}>q_{1}\right)$ is efficient even if expenditure is not permitted to vary (see Epple and Romano 1998). This is because relatively low-ability and high-income types are willing to subsidize relatively low-income and high-ability types to attend the same school. This necessarily leads to a downward-sloping boundary between the student bodies if $b$ and $y$ are independently distributed (results [d] and [e] in proposition 9). However, the efficient boundary locus will typically be downward sloping when $E[b \mid y]$ is increasing in $y$ as well, as we have found consistently in numerous computations (e.g., figure 7.6 has $E[b \mid y]$ increasing in $y$ ). Similarly, the condition in part (f) of proposition 9 that $\gamma<1$ for 


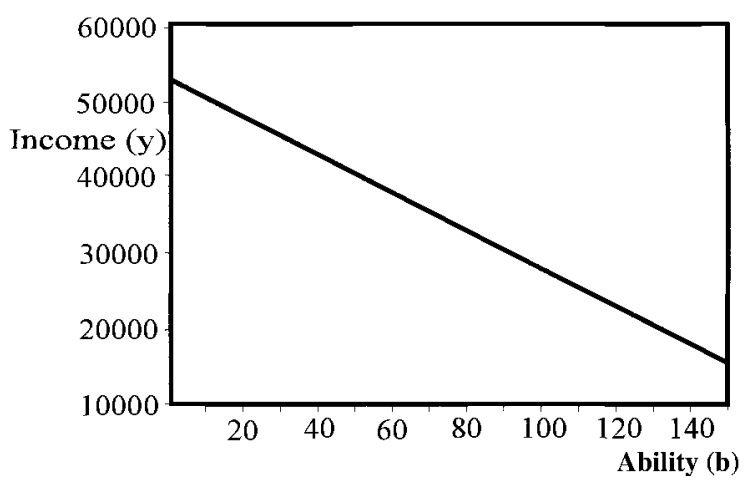

Fig. 7.6 Boundary locus for efficient allocation (parameter values are as in table 7.1)

$X_{2}>X_{1}$ is unnecessary, but neither is it very restrictive. As discussed further in section 7.6, a private schooling equilibrium also results in a (nearly) PE allocation.

This PE benchmark reveals sources of inefficiency in the equilibrium outcomes above. Welfare gains would result on average from partitioning the population into schools as in figure 7.6. We then expect that the introduction of public-school choice will tend to reduce aggregate welfare, because the neighborhood-school partition is a better approximation to the efficient partition when $E[b \mid y]$ is increasing. The neighborhood-equilibrium partition is not, however, efficient in general. The implicit pricing of schools in neighborhood equilibrium through housing prices is independent of ability, hence, incorrectly accounts for the peer-group effect. As the correlation in $(b, y)$ increases, partitioning only according to income as in the neighborhood equilibrium becomes a perfect substitute for partitioning by income and ability. While the point of partition in the neighborhood equilibrium will not generally be the efficient one since it is driven by neighborhood lines and their housing supplies, this line of argument suggests that welfare losses from choice will rise with the correlation in $(b, y)$.

Proposition 9-f indicates that expenditure "typically" rises with school quality in the efficient allocation. Consider centralized versus decentralized finance (Tiebout equilibrium) without school choice. Comparing equations (15) and (16) to equation (23), we see decentralized finance provides a first approximation to the efficient outcome. A standard voting bias from median (neighborhood) income differing from mean income arises, as does another voting bias from the distorted housing price in neighborhood 2. Nevertheless, we expect that centralization of finance (absent choice) will lower welfare.

Tables 7.1 through 7.7 present representative results from our equilibrium computations, with table 7.1 the "baseline case." Throughout, we set the minimum population ability $b_{m}=0$ and assume 


$$
\left[\begin{array}{c}
\ln b \\
\ln \left(y-y_{m}\right)
\end{array}\right]
$$

is distributed bivariate normal with covariance matrix

$$
\left[\begin{array}{cc}
\sigma_{b}^{2} & \rho \sigma_{b} \sigma_{y} \\
\rho \sigma_{b} \sigma_{y} & \sigma_{y}^{2}
\end{array}\right] .
$$

We set $y_{m}=\$ 5,000$ and use 1989 U.S. annual mean $(\$ 36,360)$ and median $(\$ 28,860)$ income to set the mean and variance of $\ln \left(y-y_{m}\right)$. We use the Cobb-Douglas utility achievement function, which (not obviously) implies that the mean of ability is irrelevant to our calculations.

We calibrate the distribution of ability so that it has the same median and mean as income. This may be motivated as follows. Consider a steady state and suppose that income is proportional to achievement. This provides a cardinalization of achievement, and this, coupled with the educational production function, induces a distribution on ability. For simplicity we calibrate ability for a case in which all students receive the same educational quality. In this case, the Cobb-Douglas achievement function implies that the logarithm of achievement is a linear function of the logarithm of ability. Hence, in this case, the steady-state lognormal distribution of income and the assumption that income is proportional to achievement imply that ability has a lognormal distribution as well. It is then convenient to choose the unit of measurement of ability so that the mean and median of ability for this case of equal school qualities equals the mean and median of income.

Two papers (Solon 1992; Zimmerman 1992) provide evidence on the correlation between fathers' and sons' income, and they are in agreement that the best point estimate of this correlation is approximately 0.4 . Hence, we set $\rho=0.4$ in the baseline case. This completes the calibration of $f(b, y)$.

We have set $\alpha=0.06$ because this implies that a household's educational expenditure would be approximately 5.6 percent $=\alpha /(1+\alpha)$ percent of its income, the actual U.S. educational percentage expenditure in 1989. Lacking evidence on the relative importance of peer group and expenditure, we also set $\gamma=0.06$ in the baseline case. The value of $\beta$ is irrelevant to our calculations, again due to the Cobb-Douglas specification.

We set the annual amortized construction cost of a house, $c$, equal to $\$ 2,500$. Last, we set the transportation cost of exercising interneighborhood choice equal to $\$ 300$ for the baseline case of choice with friction. We have computed equilibria with all parameters varied and report representative results here.

In addition to the equilibrium values in the four policy regimes, each table presents welfare changes relative to the neighborhood-school, onedistrict equilibrium. $\mathrm{CV}_{i}, i=1,2$, denotes the mean compensating variation resulting from the policy change of those who reside in neighborhood $i$ in the neighborhood-school, one-district equilibrium. Adding to (1/2) $\left(\mathrm{CV}_{1}+\right.$ 
Table 7.1

Equilibrium Properties of Four Policy Regimes

\begin{tabular}{lcccc}
\hline & $\begin{array}{c}\text { Neighborhood } \\
\text { Schools, } \\
\text { One District }\end{array}$ & $\begin{array}{c}\text { Choice, } \\
\text { One District } \\
(T=0)\end{array}$ & $\begin{array}{c}\text { Neighborhood } \\
\text { Schools, } \\
\text { Two Districts }\end{array}$ & $\begin{array}{c}\text { Choice, } \\
\text { One District } \\
(T=300)\end{array}$ \\
\hline$\theta_{1}$ & 28,565 & 36,360 & 28,565 & 18,450 \\
$\theta_{2}$ & 44,154 & 36,360 & 44,155 & 36,777 \\
$t_{1}$ & 0.051 & 0.052 & 0.049 & 0.051 \\
$t_{2}$ & 0.051 & 0.052 & 0.051 & 0.051 \\
$X_{1}$ & 1,858 & 1,880 & 958 & 1,865 \\
$X_{2}$ & 1,858 & 1,880 & 2,706 & 1,865 \\
$p_{2}$ & 3,142 & 2,500 & 4,569 & 2,800 \\
$q_{1}$ & 2.91 & 2.95 & 2.79 & 2.83 \\
$q_{2}$ & 2.98 & 2.95 & 3.05 & 2.95 \\
$y_{I}$ & & & & 10,434 \\
$C V_{1}$ & & 228 & -612 & -59 \\
$C V_{2}$ & & 87.2 & -352.0 & -181.0 \\
$\Delta p_{2}$ & & -642 & 1,428 & -342 \\
$\Delta W$ & & -163 & 232 & -291 \\
\hline
\end{tabular}

Notes: Peer measure of school $i=\theta_{i}$; tax rate in neighborhood $\mathrm{i}=t_{i}$; per-student expenditure of school $i=X_{i}$; housing price in neighborhood $2=p_{2}$; quality of school $i=q_{i}$; minimum income attending school 2 in fourth equilibrium $=y_{I} ;$ mean compensating variation relative to first equilibrium in neighborhood $i=C V_{i}$; per capita welfare change relative to first equilibrium $=\Delta W ;$ cost of exercising choice when feasible $=T$. Parameters of utility/cost function: $\alpha=0.06 ; \gamma=0.06 ; c=2,500$. Parameters of distribution function: $\rho=0.40 ; \bar{y}=36,360$; $y_{\text {med }}=28,860 ; \bar{b}=36,360 ; b_{\text {med }}=28,860$.

$\left.\mathrm{CV}_{2}\right)$ the per capita change in the housing price in neighborhood $2\left(p_{1}=c\right.$ always), $\Delta p_{2} / 2$, one obtains the per capita welfare change (denoted $\Delta W$ ) equal to per capita producer surplus plus compensating variation. We have calculated equilibrium values without redistributing the land rents for simplicity and because it is not likely to have much effect on equilibrium. In so doing, we also avoid having to specify land ownership. ${ }^{34}$

Frictionless public-school choice lowers aggregate welfare in every simulation (including all unreported ones): That is, $\Delta W$ is consistently negative. Noting that per-student expenditure changes little from the benchmark (one-district, neighborhood) equilibrium, and in fact rises (because of the positive income effect on voting from the reduction in $p_{2}$ ), it is clear the welfare loss is explained by the homogenization of peer groups. Comparing table 7.1 to 7.2, the latter having a higher (lower) $\gamma(\alpha)$, one sees that the welfare loss rises with increased weight placed on the peer group in educational achievement. (See also table 7.3.) The reason that $\mathrm{CV}_{2}$ is usually positive

34. In our computations, if all land is owned by those with income above the 3rd quartile, our equilibrium calculations would be unchanged. Skewing the top end of the net income distribution has no effect on equilibrium because no such households are ever pivotal decisionmakers in our computations. 


\begin{tabular}{lcccc}
\hline & $\begin{array}{c}\text { Neighborhood } \\
\text { Schools, } \\
\text { One District }\end{array}$ & $\begin{array}{c}\text { Choice, } \\
\text { One District } \\
(T=0)\end{array}$ & $\begin{array}{c}\text { Neighborhood } \\
\text { Schools, } \\
\text { Two Districts }\end{array}$ & $\begin{array}{c}\text { Choice, } \\
\text { One District } \\
(T=300)\end{array}$ \\
\hline$\theta_{1}$ & 28,565 & 36,360 & 28,565 & 14,392 \\
$\theta_{2}$ & 44,155 & 36,360 & 44,155 & 36,390 \\
$t_{1}$ & 0.043 & 0.043 & 0.042 & 0.043 \\
$t_{2}$ & 0.043 & 0.043 & 0.043 & 0.043 \\
$X_{1}$ & 1,561 & 1,581 & 806 & 1,564 \\
$X_{2}$ & 1,561 & 1,581 & 2,283 & 1,564 \\
$p_{2}$ & 3,254 & 2,500 & 4,456 & 2,800 \\
$q_{1}$ & 2.96 & 3.01 & 2.87 & 2.82 \\
$q_{2}$ & 3.05 & 3.01 & 3.11 & 3.01 \\
$y_{I}$ & & & & 7,598 \\
$C V_{1}$ & & 268.0 & -512.0 & -29.8 \\
$C V_{2}$ & & 101.8 & -296.0 & -196.6 \\
$\Delta p_{2}$ & & -754 & 1,202 & -554 \\
$\Delta W$ & & -192 & 196 & -340 \\
\hline
\end{tabular}

Notes: For definitions of variables, see notes to table 7.1. Parameters of utility/cost function: $\alpha=0.05 ; \gamma=0.07 ; c=2,500$. Parameters of distribution function: $\rho=0.40 ; \bar{y}=36,360$; $y_{\text {med }}=28,860 ; \bar{b}=36,360 ; b_{\text {med }}=28,860$. Change from table 7.1: $\alpha$ lower; $\gamma$ higher.

Table 7.3 Equilibrium Properties of Four Policy Regimes

\begin{tabular}{lcccc}
\hline & $\begin{array}{c}\text { Neighborhood } \\
\text { Schools, } \\
\text { One District }\end{array}$ & $\begin{array}{c}\text { Choice, } \\
\text { One District } \\
(T=0)\end{array}$ & $\begin{array}{c}\text { Neighborhood } \\
\text { Schools, } \\
\text { Two Districts }\end{array}$ & $\begin{array}{c}\text { Choice, } \\
\text { One District } \\
(T=300)\end{array}$ \\
\hline$\theta_{1}$ & 28,565 & 36,360 & 28,565 & 22,074 \\
$\theta_{2}$ & 44,155 & 36,360 & 44,155 & 38,078 \\
$t_{1}$ & 0.059 & 0.060 & 0.057 & 0.060 \\
$t_{2}$ & 0.059 & 0.060 & 0.059 & 0.060 \\
$X_{1}$ & 2,152 & 2,173 & 1,107 & 2,184 \\
$X_{2}$ & 2,152 & 2,173 & 3,119 & 2,184 \\
$p_{2}$ & 3,031 & 2,500 & 4,681 & 2,800 \\
$q_{1}$ & 2.86 & 2.89 & 2.73 & 2.82 \\
$q_{2}$ & 2.92 & 2.89 & 3.00 & 2.90 \\
$y_{I}$ & & & & 14,528 \\
$C V_{1}$ & & 188.4 & -708.0 & -62.8 \\
$C V_{2}$ & & 72.6 & -406.0 & -117.2 \\
$\Delta p_{2}$ & & -530 & 1,650 & -230 \\
$\Delta W$ & & -135 & 268 & -205 \\
\hline
\end{tabular}

Notes: For definitions of variables, see notes to table 7.1. Parameters of utility/cost function: $\alpha=0.07 ; \gamma=0.05 ; c=2,500$. Parameters of distribution function: $\rho=0.40 ; \bar{y}=36,360$; $y_{\text {med }}=28,860 ; \bar{b}=36,360 ; b_{\text {med }}=28,860$. Change from table 7.1: $\alpha$ higher; $\gamma$ lower. 
Table 7.4

Equilibrium Properties of Four Policy Regimes

\begin{tabular}{lcccc}
\hline & $\begin{array}{c}\text { Neighborhood } \\
\text { Schools, } \\
\text { One District }\end{array}$ & $\begin{array}{c}\text { Choice, } \\
\text { One District } \\
(T=0)\end{array}$ & $\begin{array}{c}\text { Neighborhood } \\
\text { Schools, } \\
\text { Two Districts }\end{array}$ & $\begin{array}{c}\text { Choice, } \\
\text { One District } \\
(T=500)\end{array}$ \\
\hline$\theta_{1}$ & 28,844 & 36,360 & 28,844 & 14,857 \\
$\theta_{2}$ & 47,876 & 36,360 & 47,876 & 37,630 \\
$t_{1}$ & 0.051 & 0.052 & 0.049 & 0.051 \\
$t_{2}$ & 0.051 & 0.052 & 0.050 & 0.051 \\
$X_{1}$ & 1,849 & 1,880 & 958 & 1,862 \\
$X_{2}$ & 1,849 & 1,880 & 2,686 & 1,862 \\
$p_{2}$ & 3,461 & 2,500 & 4,870 & 3,000 \\
$q_{1}$ & 2.88 & 2.95 & 2.77 & 2.80 \\
$q_{2}$ & 3.00 & 2.95 & 3.07 & 2.96 \\
$y_{I}$ & & & & 12,352 \\
$C V_{1}$ & & 358.0 & -612.0 & -99.8 \\
$C V_{2}$ & & 178.2 & -340 & -224 \\
$\Delta p_{2}$ & & -960 & 1,410 & -460 \\
$\Delta W$ & & -212 & 229 & -392 \\
\hline
\end{tabular}

Notes: For definitions of variables, see notes to table 7.1. Parameters of utility/cost function: $\alpha=0.06 ; \gamma=0.06 ; c=2,500$. Parameters of distribution function: $\rho=0.60 ; \bar{y}=36,360$; $y_{\text {med }}=28,860 ; \bar{b}=36,360 ; b_{\text {med }}=28,860$. Change from table 7.1: $\rho$ higher; $T$ higher.

when choice is introduced is because the housing price $p_{2}$ declines - but someone bears this loss.

Although choice causes an overall welfare loss, those residing initially in neighborhood 1 consistently gain on average from its introduction. This holds when we assign to this group a proportion of the loss in producer surplus in the housing market from choice equal to its income share (these calculations not shown in the tables).

Absent public-school choice, decentralizing the finance decision by going from one jurisdiction (or district) to two consistently increases welfare, but it also increases the dispersion of school qualities. Since peer groups in schools are unchanged, these result because of changes in educational expenditures. Not surprisingly, the housing price in neighborhood 2 rises substantially. Those initially residing in neighborhood 1 lose out on average from decentralization of finance, and this persists if they are assigned their income-proportional share of the increased producer surplus in the housing market (not shown). Hence, again, the poor are affected in the direction opposite to the average.

For the case of choice with a transport cost, we set $T=300$ in the computations, letting it vary once $(T=500$ in table 7.4). With one exception (table 7.5), we find $T=300$ (or 500) induces a large percentage of those with income below the median to exercise choice and attend school in neighborhood 2, that percentage ranging from about 72.0 to 99.7. Compare this equilibrium to frictionless choice with one district (ignoring table 7.5 for the 
Table 7.5

Equilibrium Properties of Four Policy Regimes

\begin{tabular}{lcccc}
\hline & $\begin{array}{c}\text { Neighborhood } \\
\text { Schools, } \\
\text { One District }\end{array}$ & $\begin{array}{c}\text { Choice, } \\
\text { One District } \\
(T=0)\end{array}$ & $\begin{array}{c}\text { Neighborhood } \\
\text { Schools, } \\
\text { Two Districts }\end{array}$ & $\begin{array}{c}\text { Choice, } \\
\text { One District } \\
(T=300)\end{array}$ \\
\hline$\theta_{1}$ & 32,427 & 36,360 & 32,427 & 32,102 \\
$\theta_{2}$ & 40,293 & 36,360 & 40,293 & 39,923 \\
$t_{1}$ & 0.051 & 0.052 & 0.049 & 0.051 \\
$t_{2}$ & 0.051 & 0.052 & 0.051 & 0.051 \\
$X_{1}$ & 1,869 & 1,880 & 958 & 1,863 \\
$X_{2}$ & 1,869 & 1,880 & 2,727 & 1,863 \\
$p_{2}$ & 2,822 & 2,500 & 4,268 & 2,800 \\
$q_{1}$ & 2.93 & 2.95 & 2.82 & 2.93 \\
$q_{2}$ & 2.97 & 2.95 & 3.04 & 2.97 \\
$y_{I}$ & & & & 26,966 \\
$C V_{1}$ & & 108.60 & -612.0 & -8.44 \\
$C V_{2}$ & & 27.60 & -362.00 & -4.84 \\
$\Delta p_{2}$ & & -322 & 1,446 & -22 \\
$\Delta W$ & & -92.9 & 236.0 & -17.7 \\
\hline
\end{tabular}

Notes: For definitions of variables, see notes to table 7.1. Parameters of utility/cost function: $\alpha=0.06 ; \gamma=0.06 ; c=2,500$. Parameters of distribution function: $\rho=0.20 ; \bar{y}=36,360$; $y_{\text {med }}=28,860 ; \bar{b}=36,360 ; b_{\text {med }}=28,860$. Change from table 7.1: $\rho$ lower.

moment). The voting equilibria are not much different, so expenditures vary little. The welfare loss from choice with transport costs exceeds that from frictionless choice by about the amount of the transportation costs expended. Assigning the losses in producer surplus again by income shares (not shown in the tables), we find that the greater welfare loss under choice with transport costs is borne largely by those with below-median income. Those that exercise choice obviously pay the transportation costs. Those that choose not to commute face a substantially diminished peer group.

The exceptional case of table 7.5 has low correlation of income and ability. The per capita welfare loss relative to the benchmark equilibrium equals only $\$ 17.65$. Because the peer group difference is small in the neighborhood equilibrium, little incentive to exercise choice is present, and less than 9 percent of those with below median income do so. Note, too, that the price difference between neighborhoods $\left(p_{2}-c\right)$ is only $\$ 322$ in the benchmark equilibrium for the parameter settings in table 7.5. This is another manifestation of the limited value of the peer quality gain to migration in this case. By contrast, for the other cases we report in the tables, the housing price differential in the benchmark case is much larger, ranging between $\$ 530$ and $\$ 960$. Table 7.6 has a higher construction cost of housing than in the baseline case. This has a negative income effect, manifest in lower schooling expenditures in all equilibria and less exercise of choice when there is a transportation cost.

Table 7.7 has a more right-skewed income distribution, holding constant 


\begin{tabular}{lcccc}
\hline & $\begin{array}{c}\text { Neighborhood } \\
\text { Schools, } \\
\text { One District }\end{array}$ & $\begin{array}{c}\text { Choice, } \\
\text { One District } \\
(T=0)\end{array}$ & $\begin{array}{c}\text { Neighborhood } \\
\text { Schools, } \\
\text { Two Districts }\end{array}$ & $\begin{array}{c}\text { Choice, } \\
\text { One District } \\
(T=300)\end{array}$ \\
\hline$\theta_{1}$ & 28,565 & 36,360 & 28,565 & 21,416 \\
$\theta_{2}$ & 44,155 & 36,360 & 44,155 & 37,748 \\
$t_{1}$ & 0.048 & 0.049 & 0.045 & 0.049 \\
$t_{2}$ & 0.048 & 0.049 & 0.049 & 0.049 \\
$X_{1}$ & 1,752 & 1,773 & 873 & 1,790 \\
$X_{2}$ & 1,752 & 1,773 & 2,612 & 1,790 \\
$p_{2}$ & 4,605 & 4,000 & 5,952 & 4,300 \\
$q_{1}$ & 2.90 & 2.94 & 2.78 & 2.85 \\
$q_{2}$ & 2.97 & 2.94 & 3.05 & 2.95 \\
$y_{I}$ & & & & 13,644 \\
$C V_{1}$ & & 208.0 & -556.0 & -50.4 \\
$C V_{2}$ & & 47.0 & -298.0 & -126.6 \\
$\Delta p_{2}$ & & -606 & 1,346 & -306 \\
$\Delta W$ & & -166 & 247 & -241 \\
\hline
\end{tabular}

Notes: For definitions of variables, see notes to table 7.1. Parameters of utility/cost function: $\alpha=0.06 ; \gamma=0.06 ; c=4,000$. Parameters of distribution function: $\rho=0.40 ; \bar{y}=36,360$; $y_{\text {med }}=28,860 ; \bar{b}=36,360 ; b_{\text {med }}=28,860$. Change from table 7.1: $c$ higher.

Table 7.7 Equilibrium Properties of Four Policy Regimes

\begin{tabular}{lcccc}
\hline & $\begin{array}{c}\text { Neighborhood } \\
\text { Schools, } \\
\text { One District }\end{array}$ & $\begin{array}{c}\text { Choice, } \\
\text { One District } \\
(T=0)\end{array}$ & $\begin{array}{c}\text { Neighborhood } \\
\text { Schools, } \\
\text { Two Districts }\end{array}$ & $\begin{array}{c}\text { Choice, } \\
\text { One District } \\
(T=300)\end{array}$ \\
\hline$\theta_{1}$ & 28,565 & 36,360 & 28,565 & 22,860 \\
$\theta_{2}$ & 44,155 & 36,360 & 44,155 & 38,534 \\
$t_{1}$ & 0.051 & 0.052 & 0.048 & 0.053 \\
$t_{2}$ & 0.051 & 0.052 & 0.051 & 0.053 \\
$X_{1}$ & 2,300 & 2,326 & 839 & 2,365 \\
$X_{2}$ & 2,300 & 2,326 & 3,708 & 2,365 \\
$p_{2}$ & 3,142 & 2,500 & 5,139 & 2,800 \\
$q_{1}$ & 2.94 & 2.99 & 2.77 & 2.91 \\
$q_{2}$ & 3.02 & 2.99 & 3.11 & 3.00 \\
$y_{I}$ & & & & 12,905 \\
$C V_{1}$ & & 200.0 & -824.0 & -31.4 \\
$C V_{2}$ & & -126.4 & -134.8 & -192.0 \\
$\Delta p_{2}$ & & -642 & 1,996 & -342 \\
$\Delta W$ & & -284 & 519 & -283 \\
\hline
\end{tabular}

Notes: For definitions of variables, see notes to table 7.1. Parameters of utility/cost function: $\alpha=0.06 ; \gamma=0.06 ; c=2,500$. Parameters of distribution function: $\rho=0.40 ; \bar{y}=45,000$; $y_{\text {med }}=28,860 ; \bar{b}=36,360 ; b_{\text {med }}=28,860$. Change from table 7.1: variance $y$ higher. 
the median income. This is associated with greater inframarginal demand for segregation by the relatively wealthy. This amplifies the aggregate welfare loss from frictionless choice and the aggregate welfare gain from neighborhoods becoming jurisdictions.

An important warning concerning our normative analysis is that our model abstracts from potential productivity gains from increased competition among schools for students. Hoxby (2000a) finds such gains when district competition for students increases, as would occur with finance decentralization. Increased school choice within districts might have similar effects. Our model emphasizes the likely sorting effects of such policies. Although we do not by any means believe our welfare findings to be definitive, we think it crucial in policy design to anticipate potential changes in school composition.

\subsection{Vouchers and Private Schooling}

We have examined the consequences of introducing public-school choice into a school district. One can interpret this choice policy as a voucher equal to the average cost of schooling that can be used at any public school. Now we examine the consequences of allowing vouchers to be used at a private school. We focus on a voucher policy that will eliminate the public sector, where the comparison will be between the allocations in panels B and C of figure 7.1 .

The choice program we examine provides a voucher of exogenous amount to any student who chooses to attend a school other than his neighborhood public school, the voucher financed out of the income tax (adjusted to cover the cost of the voucher). Importantly, private schools admitting voucher students are unconstrained in all regards. Private schools can pursue whatever admission and tuition policies they would like, including selective admissions, tuition on top of the voucher, and giving of scholarships and fellowships. Hence, we examine a laissez-faire voucher system as described by Friedman (1962). Because of the free reign of the market (and the magnitude of the voucher), the voucher equilibrium can also be interpreted as an equilibrium with only private provision allowed, but with a linear income tax that redistributes income so everyone can pay the average cost of schooling. As we will discuss further, alternative voucher policies that place restrictions on schools accepting voucher students may have different effects.

We modify the model above in two ways. Because private schools have incentives to become very specialized in the student bodies they serve, we introduce economies of scale into the provision of schooling, and this keeps them from becoming infinitely specialized. We do this by making an element of school cost independent of quality-producing inputs, and these 
"custodial costs" are first rising and concave in the number of students, then rising and convex. Expenditure on quality-producing inputs $(X)$ is in addition to the latter costs and continues to exhibit constant returns to scale. For any per-student expenditure on quality, the average cost is then $U$-shaped in the number of students with the same efficient scale.

The second modification of the model is to simplify by exogenously fixing the expenditure per student on quality in every school, public or private, at the same level. All variation in school quality is then due to variation in the peer group. This simplification does not affect the qualitative nature of sorting in equilibrium. We note the expected quantitative effects of allowing expenditure variation. The production function of educational quality $q$ continues to be as in equation (2), does utility, except now $X$ is fixed exogenously in all schools. Other than through effects on the tax rate, none of our following welfare calculations are affected by the level of $X$ because of the Cobb-Douglas specification of utility and achievement. Later we consider differences in productivity of public and private schools, but we assume initially that they are equally productive.

Details of the modified calibration are in Epple and Romano (1998). We calibrate the cost function of schooling so that the efficient scale of operation is 3.03 percent of the population, with schooling cost of approximately $\$ 4,200$ per pupil. How these costs break down between custodial costs and expenditure on quality-enhancing inputs is irrelevant to the calculations we do (again due to the Cobb-Douglas specification). The calibrated utility function is the same as in the benchmark model above. We use the same calibration of the income distribution but with the simplification that minimum income equals 0 . Hence, we also set $c=0$. Again we set the correlation between income and ability equal to 0.4 . We calibrate the ability distribution using the same (steady-state) strategy as above, but here we take account of the fact that the ratio of workers to school-age children is 2.6 , implying a tighter ability distribution with mean 13,600 and median 11,300 .

Private schools are modeled as in Epple and Romano (1998). They choose tuition and admission policies to maximize profits, and there is free entry and exit. They can determine a student's ability and his or her household income, implying that they can condition tuition and admission on these characteristics as competition allows. They take as given every student type's willingness to pay for school quality. Assuming there is adequate demand for quality of schooling for private schools to arise, equilibrium satisfies some basic properties, which we briefly summarize. ${ }^{35}$

Refer to panel A of figure 7.1, which depicts the case in this calibration with public school choice and no voucher, where four private schools then

35. Precise equilibrium fails to exist due to a variant of the integer problem, so we calculate an approximate equilibrium. See Epple and Romano (1998) for details. 
enter and each earns (approximately) zero profits. The private schools serve nonoverlapping student sets as delineated by the four boundary loci in the figure. Private schools each serve student bodies of size below the efficient scale (the density of types is low in the upper right of the $[b, y]$ plane), in a fashion similar to that of Chamberlin monopolistically competitive equilibria. Within each private school, relatively lower-ability and higherincome types mix with relatively higher-ability and lower-income types. Equilibrium pricing entails cross-subsidization within a private school from the former to the latter students. Essentially, the higher-income types are purchasing the positive peer effect of the higher-ability types. In fact, the peer externality is fully internalized: Prices to all students on the margin of switching schools equal social marginal cost as in equation (19), with inframarginal students paying somewhat higher prices as schools take away consumer surplus. ${ }^{36} \mathrm{~A}$ strict quality hierarchy of private schools always results. Because demand for schooling quality rises with income, the lack of entry barriers (other than a free public schooling alternative!) leads the private sector to refine the quality of schooling limited only by economies of scale. The internalization of the peer effect implies an efficient allocation of the private-school students among the private schools that enter. When public schools remain, they are of lower quality than any private school.

The equilibrium with the voucher has a $\$ 4,200$ voucher with allocation of types into schools as depicted in panel B of figure 7.1. This voucher, equal to average educational cost at the efficient scale, wipes out public provision. Because we have fixed quality-enhancing expenditures and provided a voucher that can cover these costs, the pricing flexibility of private schools permits them to engender student bodies that are more efficient than a public school would attract. This is not, however, to suggest a Pareto improvement from introducing a $\$ 4,200$ voucher relative to the no-voucher equilibrium of panel A. Private schools cream-skim high-ability students as they enter with negative externalities for those of lower abilities who end up in schools with weakened peer groups. Equilibrium properties are as in panel A of figure 7.1, but, obviously, there is substantially more income and ability stratification and variability in school qualities. There are thirty-four private schools, all serving less than (but close to) 3.03 percent of the population of students.

If expenditures are allowed to vary in public and private schools, the level of the voucher necessary to eliminate public provision depends primarily on the following factors. Although private schools have the increased advantage of being able to set expenditures as their clientele prefers, per-student expenditure in public schools is subsidized by taxation of private-school students (maintaining here the assumption of majority choice of tax-

36. Our warnings discussed in section 7.5 concerning efficiency measures apply here as well. 
expenditure policy). ${ }^{37}$ At the same time, as the voucher rises and students are drawn into the private sector, political support for taxation to finance private schools declines. ${ }^{38}$ Due to the latter fact, the voucher need not be too high before the public sector is eliminated. Importantly, the qualitative nature of the equilibrium allocation - for example, the "diagonalized stratification across private schools"-remains with expenditure variation.

We now compare the voucher equilibrium to the neighborhood schooling equilibrium with neighborhood lines drawn to minimize schooling costs. Hence, the neighborhood equilibrium has thirty-three equally sized schools with allocation of types into schools as depicted in panel $\mathrm{C}$ of figure 7.1. Private schools would be unlikely to enter without any voucher.

The panels of figure 7.7 provide information by student type on the effects of a voucher that covers average schooling cost. The upper panel shows the welfare effect as a percentage of income, equal to the (negative of the) compensating variation from moving to the voucher equilibrium. Housing prices everywhere drop to their construction cost (0) in the voucher equilibrium. In the welfare calculation, we assume that households own the land where they reside in the initial equilibrium, so the declines in housing prices are irrelevant to welfare (i.e., households pay themselves less rent). The welfare change is then entirely due to changes in school quality and payments for school, with the latter being equal to any tuition after the voucher plus tax changes. Tax changes are close to zero, since the tax required to finance the voucher approximately equals the tax otherwise used to finance the public school system. Thus, tax changes can be ignored in the discussion. Keep in mind that tuition varies continuously with student ability and income in each private school. Thus, although the average after-voucher tuition is (approximately) equal to zero, virtually every student will pay a net positive or negative tuition in the voucher equilibrium.

Before discussing the welfare effects, it is useful to describe the lower panel of figure 7.7. This panel shows percentage changes in "normed achievement," which equals our achievement measure raised to the power $1 / \beta$ (see equation [2] for achievement, $a$ ). Normed achievement can be given several interpretations. First, its changes are proportional to changes in school quality (with factor of proportionality $1 / \beta$ ). Second, proportional changes in normed achievement due to changes in school quality have equivalent effects on utility and achievement as the same proportional change in own student ability. Third, related to the latter and given our calibration of the utility function, changes in normed achievement approximate changes in future earnings while employed.

37. The expenditure flexibility of private schools need not just imply relatively high expenditure levels. With our laissez-faire voucher policy, private schools may form that serve the poorest students and use some voucher money to provide all students with fellowships. Of course, the voucher policy might be modified to prevent this.

38. The effects of this on voting equilibrium are analyzed in Epple and Romano (1996). 

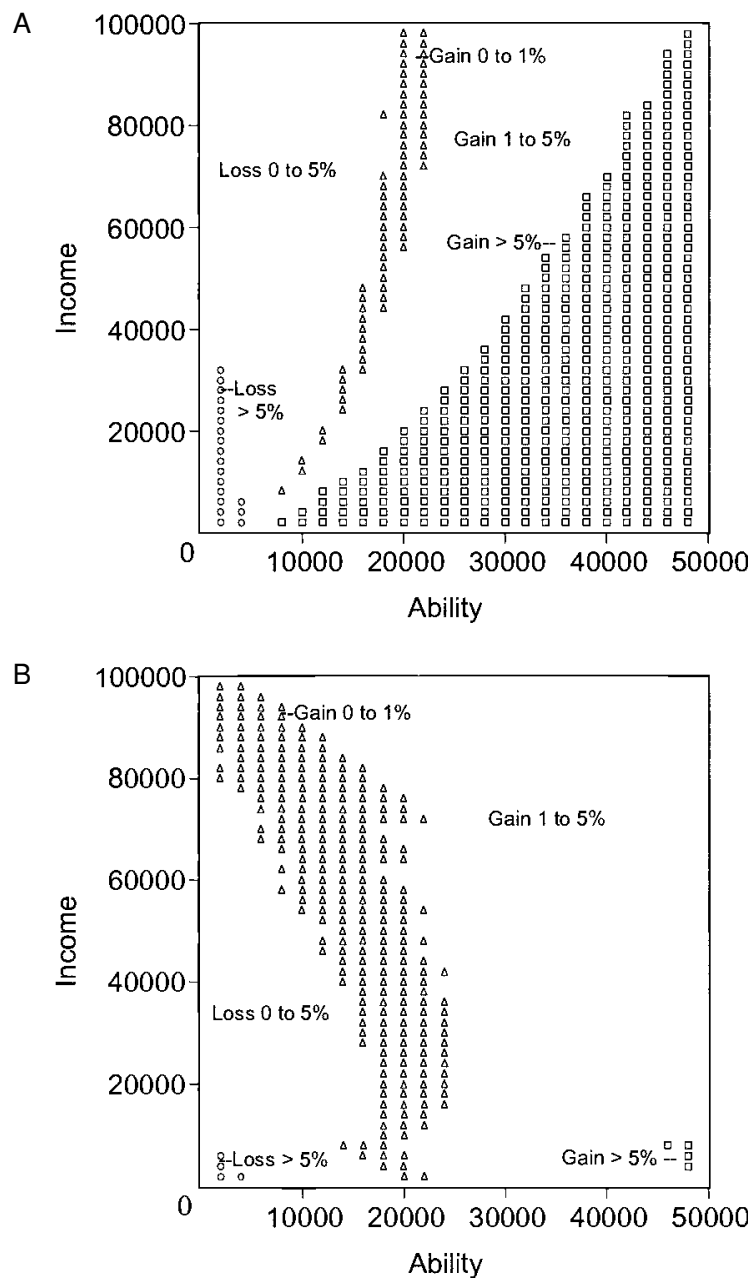

Fig. 7.7 $A$, Welfare effects of voucher; $B$, achievement in private schools relative to public schools

The average welfare change from the voucher is only about $\$ 55$. It is positive because the student sorting is Pareto efficient in the voucher equilibrium. It is small in part because the neighborhood equilibrium has many schools that also sort students by ability and income to the extent that income and ability are correlated. For example, the average welfare gain in going from the equilibrium in panel $\mathrm{A}$, which has little sorting, to the voucher equilibrium is larger (although still only about $\$ 185$ ). If private schools could choose their expenditure levels, the average gain would be larger as well.

Although, on average, there are gains from moving to the voucher equilibrium from the neighborhood school equilibrium, the effects of the 
voucher are not distributed equally. Gains and losses for many are substantial relative to the average effect. Beginning at the lower right of panel A of figure 7.7 and moving counterclockwise, we see that the welfare gains decline and ultimately become negative. Students in the lower right triangle in this panel gain the most as a percentage of their household income. These are poor but relatively high-ability students. As one can see from panel B of this figure, most of these students are in better schools in the voucher equilibrium than in the neighborhood school equilibrium, because private schools sort students on ability to the benefit of higher-ability students. Comparing these two panels, we see that some of these students (e.g., those with low income and moderate ability) end up in lower-quality schools but nonetheless have a welfare gain. They are above-average students in the schools they attend, and they thus generate a positive peer externality. As a result, they obtain a negative net tuition (i.e., a scholarship), yielding a financial gain sufficiently large to offset the monetary value to them of their achievement loss.

More generally, tuition discounts are part of the gain to all relatively high-ability students. However, inspection of the right portion of panel A reveals that gains decline as income rises for a given ability. High-ability students gain less from switching to the voucher equilibrium primarily because they were in relatively high-quality neighborhood public schools.

Moving sufficiently counterclockwise in the $(b, y)$ plane, one finds welfare losses. Thus, welfare losses accrue to relatively low-ability students. It is useful to consider separately the impacts on high- and low-income students in this low-ability group. As can be seen from panel B of figure 7.7, the highincome, low-ability students are in higher-quality schools in the voucher equilibrium. They nonetheless experience a welfare loss because they pay a tuition premium in the voucher equilibrium to gain access to schools with relatively high-quality peer group. Turning to low-income members of the low-ability group, we see from panel B that they attend lower-quality schools; they do not have high enough income to be willing to pay the tuition premium to attend a higher-quality school. From panel B, we see, not surprisingly, that they also experience a welfare loss. The poorest and lowest-ability students end up in worse schools and have to pay a positive net tuition.

Although the average welfare gain is positive, a majority equal to about 60 percent is worse off from the voucher. We emphasized earlier that our analysis abstracts from potential productivity gains from increased competition for students (see Hoxby, chap. 8 in this volume). On top of the evidence, there are several reasons to believe that competing private schools will more efficiently provide education (for given student body) than will schools in a neighborhood system. Most important, students attending a low-productivity private school can switch to a new efficient entrant at little or no cost. Neighborhood public schools are much more insulated from 
competition, because switching schools would require moving and paying a housing price premium. Households with children at different educational levels would be frequently forced to switch schools for every child when moving between neighborhoods, sometimes curtailing an incentive to do so. It is true that land owners in a neighborhood have incentives to foster efficient public schooling, but their control is limited at best. For these reasons, we now examine how our welfare results vary with increases in the relative productivity of private schools.

Specifically, we compute the average welfare change and the proportion that gains from the voucher as a function of the relative productivity of private versus public schools. Before discussing the results reported in the panels of figure 7.8, we provide several pieces of information for interpret-
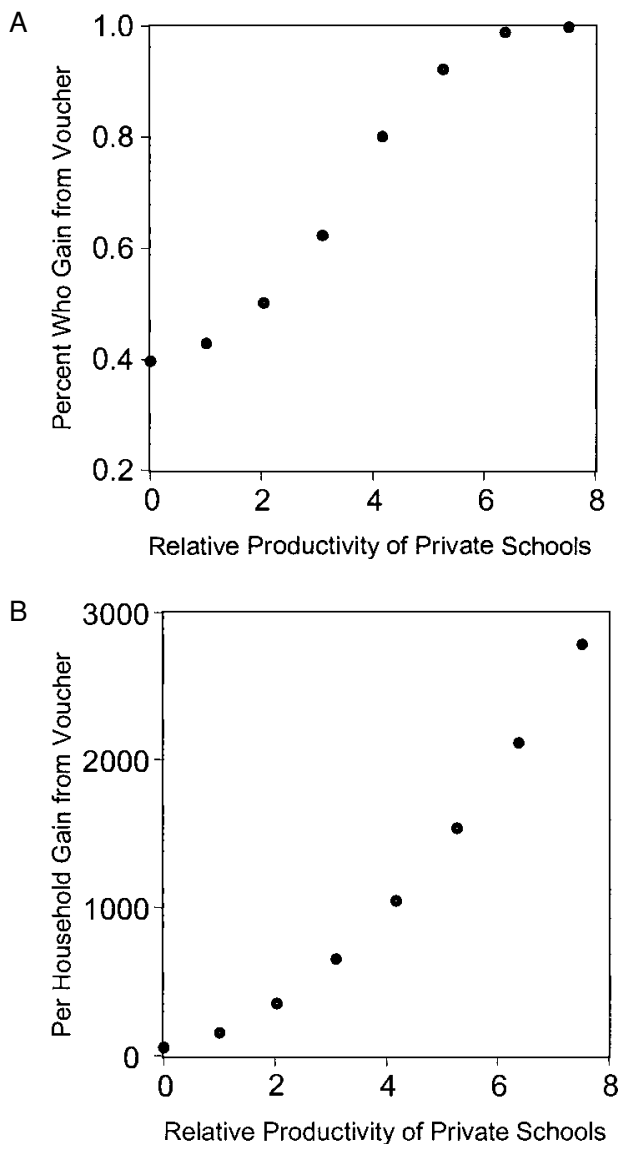

Fig. 7.8 $A$, Percent who favor voucher as function of productivity of private relative to public schools; $B$, per-household gain from voucher as function of productivity of private relative to public schools 
ing the productivity measure on the horizontal axis. This scale can be interpreted as the percentage gain in earning power the student would acquire in private school relative to the earning power the student would acquire in an otherwise identical public school. ${ }^{39}$ Thus, a productivity value of 2 implies that a student graduating from private school would earn 2 percent more than if the student graduated from a public school that expended the same resources and had the same peer group. With the available empirical evidence, this productivity measure can also be related to differences in achievement test scores. For example, Neal and Johnson (1996, 874) estimate that a 1 standard deviation improvement in the Armed Forces Qualification Test (AFQT) score translates into a 20 percent increase in wages. Thus, 2 on our productivity scale would be comparable to a test score improvement in private relative to public school of $1 / 10$ of a standard deviation in the AFQT. Elsewhere in this volume, Peterson et al. (chap. 4) estimate that voucher experiments have improved student test scores by about $1 / 3$ of a standard deviation. Assuming the Neal-Johnson coefficient on test scores applies to the tests used in the voucher experiments, the test score improvement in the voucher experiments would imply a value of roughly 6 on our productivity scale. Hoxby (2000a) estimates that a 1 standard deviation increase in her measure of public school choice would increase income at age thirty-two by 4 percent, a value of 4 on our productivity scale. ${ }^{40}$

Given the preceding interpretations of the horizontal axis in figure 7.8, we now turn to discussion of the results reported in those figures. The bottom panel translates a given percentage differential in earning power into an average annual household dollar gain from introducing the voucher. For example, a 4 percent differential in productivity between private and public schools translates into a difference in average household earning power of about $\$ 1,000$ in 1990 dollars. The upper panel reports the proportion that gains from the voucher. With a productivity value of 2 , a narrow majority of the population gains from the voucher. With a value of 4 , roughly 80 percent of the population gains from the voucher. If relative productivity values exceed about 6 , then everyone is better off in the voucher equilibrium.

The reader must, again, keep in mind that our predictions about the effects of a voucher depend on the particular voucher policy. Three types of variations in the voucher policy analyzed here have been considered by policymakers and enacted in some instances. First, we have analyzed a univer-

39. These calculations use the normed-achievement function previously discussed and the fact that normed achievement can be interpreted as future earnings, the latter implied by our calibration strategy. We can then multiply the achievement function in public schools by a constant greater than 1 to obtain an achievement function for private schools that conforms to a given percentage gain in earning power.

40. In table 4, Hoxby (2000a, 1227) reports that a regression of $\ln$ (income) on her school choice measure yields a coefficient of 0.151 . A standard deviation of her school choice measure is 0.27 . Multiplying the preceding two numbers yields the percentage reported in the text. 
sal voucher of sufficient magnitude to cover average schooling cost, leading to elimination of the public sector. Universal vouchers that cover only part of schooling cost would be taken up only by those with sufficiently high demand for educational quality, with the rest still attending public schools. Nechyba analyzes such partial vouchers in a multidistrict setting in his chapter of this volume. He shows that (many) households taking up vouchers will relocate to districts with lower housing prices, with important local fiscal externalities on remaining public schools. In our single-district environment, partial vouchers would likewise lead to movement to initially poorer neighborhoods, but without such fiscal externalities since public school finance is not localized in our case. See Epple and Romano (1998, 1999) for analysis of partial vouchers in a single-district case with homogeneous public schools (e.g., due to public school choice).

Rather than being universally available, vouchers might be targeted to particular types of students. Nechyba (chap. 5 in this volume) also analyzes targeting to poor districts. Fernández and Rogerson (chap. 6 in this volume) examine the political economy of means- (income-) tested vouchers in their chapter. The three privately funded voucher programs evaluated in Peterson et al. (chap. 4 in this volume) are all targeted to low-income students (and are partial vouchers). Figlio and Page (chap. 2 in this volume) argue that school accountability plans that accurately measure school productivity and that make vouchers available to students in low-productivity schools will poorly target vouchers to the most disadvantaged. In Epple and Romano (1999), we ask whether appropriately targeted vouchers might yield benefits to everyone by maintaining or improving upon status quo stratification, while increasing productivity by injecting private-school competition into the education system.

The answer to the latter question depends on a third element of voucher policies. Rather than a laissez-faire voucher policy, participating private schools might face regulations, most importantly regarding their admission or tuition policies. The Florida voucher program, for example, requires participating private schools to accept exactly the voucher for tuition and to accept every voucher-financed student (or, if capacity-constrained, to admit from the pool of voucher-financed students with equal probabilities). Assuming enforceability of such regulations (a serious concern), they can be highly relevant to the effects of voucher system. In Epple and Romano (1999), we show that a laissez-faire voucher whose magnitude varies with student ability (from which the peer externality derives) will continue to lead to a highly stratified equilibrium. We show further, however, that a voucher properly targeted to ability combined with a requirement on participating schools to take exactly the voucher for tuition for any students the school chooses to admit can lead to significant private school entry and thus productivity gains, without significant effect on stratification. Everyone gains here. 


\subsection{Discussion and Conclusions}

Many models of multijurisdictional equilibrium are structured so that differences in tax and expenditure policies across jurisdictions are the only force leading to stratification of population across jurisdictions. These models have been quite fruitful in studying a variety of policy issues related to state and local government finance. In investigating school finance policy issues, it is natural to turn to those models to understand the effects of changing the structure of school finance. In geographic areas in which students are served by a single school in each district, these models should give reasonable guidance, particularly in studying finance policies that entail only partial equalization across jurisdictions.

Unfortunately, these conditions are almost never met. As we noted in section 7.1, the vast majority of children in the United States go to school in multischool districts. Central-city districts are virtually all multischool districts. Thus, many students go to school in districts that have dozens of schools. The second difficulty with using the traditional model to study school policy is that it gives either no predictions or incorrect predictions in cases where there is full equalization of expenditure per student or in the study of intradistrict public school choice. The difficulty lies in the common assumption that stratification of the population across schools is driven by expenditure differences and that stratification does not arise when expenditures are equalized.

Even a cursory look at the stratification of households across neighborhood schools in large urban districts is sufficient to put to rest the notion that there is no stratification among schools in a district when expenditures are equalized. We have shown in this paper that there is likely to be little or no change in stratification when expenditures are equalized in neighborhood school systems. School quality differences arising from peer effects give rise to housing price differentials across neighborhoods that are sufficient to sustain stratification. Thus, although expenditure equalization may lead to some reduction of school quality differences, equalization of school quality will generally not arise when expenditures per student are equalized.

Our paper provides insights into public school choice programs and offers a foundation for addressing many issues related to public school choice. We noted earlier that, although many states have interdistrict school choice programs, few students participate in such programs. This is as our model would predict, because districts that are prospective recipients of choice students will resist accepting such students. To see why, consider two districts, D1 and D2, and a student from D1 who wishes to attend school in D2. For simplicity, suppose that each district has only one school. It is easy to see that D2 will resist if the funding the student brings from D1 is less than the expenditure per student in D2. Suppose then that the choice program compensates for any such funding disparities. Our model predicts 
that D2 will nonetheless resist. In the absence of funding disparities, students will wish to transfer from schools with low average peer ability to those with high average peer ability. The clientele of the prospective recipient school will resist accepting such students since, on average, they will be of lower peer ability than the incumbent students. In practice, in states where district participation in interdistrict choice programs is voluntary, high-income districts typically opt out. In states where such formal opting out is not permitted, de facto opting out is nonetheless likely to occur, as prospective recipient districts give priority to local residents and then "find" that they have little or no excess capacity to serve students from outside the district.

Of course, the same incentives to resist choice students arise within districts. Within-district programs often tackle this resistance by requiring schools to select at random from their applicant list if they are oversubscribed. Of course, a recipient school may still be less welcoming to students from outside the neighborhood than to students from inside the neighborhood, but such informal resistance is likely to be muted if district administrators are sufficiently committed to the choice program. Students exercising choice may then find that the gain in school quality is sufficient to justify living with any residual resistance. Such resistance may, however, be similar to the role of our transportation cost variable, $T$, in discouraging students from the lowest-income households from attending a higher-quality choice school.

Our model points to potential unintended consequences of public school choice programs. For example, suppose, again, that there are two districts, D1 and D2. Suppose now that D1 has two neighborhood schools, A and B, and D2 has one school, C. For simplicity, let the three schools be of equal size. Suppose that low- and high-income students are in district D1, and middle-income districts are in D2. Specifically, let the attendees of A be lowincome students, with B serving high-income students, and C serving middle-income students. Thus, the ordering of school qualities is A, C, B. How could such an allocation be an equilibrium? One could easily construct realistic examples in which tax base per student in D1 would be comparable to tax base per student in D2, so that equilibrium would be characterized by little difference in spending per student in the two districts. With $E[b \mid y]$ increasing in $y$, the ordering of school qualities A, C, B would then primarily reflect differences in peer qualities.

Beginning with such an equilibrium, consider the effect of introducing a frictionless intradistrict choice program in D1. What are the possible equilibria with this choice program? The equalization of peer qualities in D1 means that there will no longer be stratification within districts. There will, however, be stratification across districts. Thus, one possible equilibrium is that the high-income households will remain in D1, middle-income households will move to D1, and the poor will move to D2. The other possible 
equilibrium is that the high-income households will move to D2 and the middle-income households will move to D1. ${ }^{41}$ What are the effects on school quality? In the first case, students in poor households receive a worse education after introduction of the choice program. They face the same peer quality as before the change and reside in a district where the tax base is lower than in the original equilibrium. In addition, the pivotal voter is poorer than in the original equilibrium, so there will be a decline in spending due both to the lower tax base and to the lower willingness of the pivotal voter to tax in support of education. Middle-income students will probably gain because they move to a district with higher average tax base and higher average peer quality. The effect on high-income students is ambiguous, because their district's tax base per student rises but choice causes the quality of peer students to fall. In the second case, the effect of the change on students in low-income households is ambiguous, depending on whether peer effects or expenditure effects are more important. Students in high-income households will receive higher-quality education than before the change, and students in middleincome households will receive lower-quality education.

The preceding discussion illustrates the potential of our model for anticipating consequences of public school choice programs. ${ }^{42}$ Because choice programs have been undertaken by a number of central-city districts, the possibilities raised in this example cannot be easily dismissed. Metropolitan areas typically contain suburban districts that have lower average income than average income in the wealthiest central-city neighborhoods. Thus, there is a very real possibility that introduction of choice programs in central-city districts will induce exodus from the city by the high-income households and entry by middle-income households. Of course, a central-city district may nonetheless decide that the choice program should be undertaken. The point of the example is to illustrate that our model provides a vehicle for thinking through the likely consequences of such policy changes.

\section{Appendix}

\section{The Existence and Multiplicity of Differentiated Equilibria in the Neighborhood Model}

Proposition A1 identifies the multiplicity of equilibria that arise in the neighborhood schooling model with $N$ neighborhoods. It also proves existence of such equilibria, thus proving part (a) of proposition 2 .

41. If one thinks of the multischool district as a central city, then the second is the more likely outcome, because forces not in our model lead the poor to live in cities (Glaeser, Kahn, and Rappoport 2000).

42. Incorporating a private schooling sector is obviously of interest, an extension that we are currently pursuing. 
Proposition A1. Divide the $N$ neighborhoods into $k(\leq N)$ sets, each set consisting of all neighborhoods having the same housing capacity. Let $m_{i}, i=$ $1,2, \ldots, k$, equal the number of neighborhoods in set $i$. The maximum number of neighborhoods/schools having different peer groups in an equilibrium equals $N$. There are \# $\equiv N ! /\left(m_{1} ! \cdot m_{2} ! \cdots m_{\mathrm{k}} !\right)$ distinct such equilibria.

Proof. Obviously, $N$ is the maximum number of different school qualities that is feasible in an equilibrium. The number of distinct ways neighborhoods can be ordered by their housing capacities is \#. We now show each distinct order is consistent with an equilibrium having $N$ different school qualities by construction. Refer to figure 7.3 for an example. (Note that figure 7.3 has three neighborhoods but not necessarily with distinct housing capacities [population sizes], the latter depending on $f(b, y)$.)

Take any order of neighborhoods and number them $1,2, \ldots, N$. Let $F_{y}(y)$ denote the marginal c.d.f. of $y$ in the population. Set $y_{0} \equiv y_{m}$ and find $y_{i}, i=$ $1,2, \ldots, N-1$, such that $F_{y}\left(y_{i}\right)-F_{y}\left(y_{i-1}\right)$ equals the land capacity of neighborhood $i$. Recalling that we normalized the population to 1 and also setting the aggregate housing capacity equal to 1 , it is clear that the ordering of neighborhoods results in a unique vector $\left(\mathbf{y}_{1}, \mathbf{y}_{2}, \ldots \mathbf{y}_{\mathrm{N}-1}\right)$. These delineate the equilibrium partition. Set $y_{N} \equiv y_{x}$, and let

$$
\theta_{i} \equiv \frac{\int_{y_{i-1}}^{y_{i}} \int_{b_{m}}^{b_{x}} b f(b, y) d b d y}{\int_{y_{i-1}}^{y_{i}} \int_{b_{m}}^{b_{x}} f(b, y) d b d y}=\frac{\int_{y_{i-1}}^{y_{i}} E[b \mid y] \cdot\left[\int_{b_{m}}^{b_{x}} f(b, y) d b\right] d y}{\int_{y_{i-1}}^{y_{i}} \int_{b_{m}}^{b_{x}} f(b, y) d b d y}
$$

denote the implied peer quality measures. Since $E[b \mid y]$ is increasing, $\theta_{1}<\theta_{2}$ $<\ldots<\theta_{N}$. Then, since $X_{i}$ is constant across neighborhoods, the $q_{i}$ s also ascend. Let $p_{i}$ denote the housing price in neighborhood $i$, and set $p_{1}=c$. Find $p_{i}, i=2,3, \ldots, N$, recursively from

$$
U\left[y_{i-1}(1-t)-p_{i}, a\left(q_{i}, b\right)\right]=U\left[y_{i-1}(1-t)-p_{i-1}, a\left(q_{i-1}, b\right)\right],
$$

noting that equation (3) implies unique solutions independent of $b$. Since $q_{i}>q_{i-1}, p_{i}>p_{i-1}$. By equation (1) the assigned residential choices are utility maximizing, and the housing markets clear by construction. We have then described an equilibrium consistent with the given ordering of neighborhoods. A distinct equilibrium can be so constructed from each of the distinct orderings.

\section{Voting Equilibrium}

To solve for voting equilibrium, we follow the same methodology employed in Epple and Romer (1991). Take as given the household's residence and consider the preference mapping in the $(X, t)$ plane for Cobb-Douglas utility function (see equation [2]). An indifference curve is defined: $U(X, t$; $y, p, b, \theta)=$ constant. Using equation (2), it is straightforward to confirm the following: 
LEMma 1. (a) Indifference curves in the $(X, t)$ plane are upward sloping and concave, with lower (southeasterly) indifference curves corresponding to higher utility. ( $b)$ The indifference curve mapping is independent of $b$ and $\theta$, depending only on $y / p$ and $\alpha$. (c) As we look across households, the slope of indifference curves through any point $(X, t)$ increases with $y / p$. Hence, any pair of indifference curves cross once at most.

Lemma 1 implies that households with higher $y / p$ have a stronger preference for $(X, t)$ in the following sense. If a household is indifferent to choices $\left(X_{2}, t_{2}\right)$ and $\left(X_{1}, t_{1}\right)$ where $X_{2}>X_{1}$ and $t_{2}>t_{1}$, then all households with higher (lower) $y / p$ strictly prefer point $\left(X_{2}, t_{2}\right)$ (point $\left.\left[X_{1}, t_{1}\right]\right)$ over the alternative. The latter can be verified using lemma 1 by drawing indifference curves in the $(X, t)$ plane (see figure $7 \mathrm{~A} .1$ for example). It also follows that, whether or not the feasible choice set of $(X, t)$ values voters face is well behaved (e.g., convex):

Lemma 2. A most preferred choice of a voter with median preference (i.e., median $y / p$ ) from the feasible choice set is a majority voting equilibrium. Only a most-preferred choice of a voter with median preference is a voting equilibrium if the density of the preference parameter $y / p$ is positive in the vicinity of the median.

PROOF. The argument follows the graphic technique of Epple and Romer (1991), and is presented here for the reader's convenience. Refer to figure 7A. 1 where $U_{\text {med }}$ is an indifference curve of a voter with median preference, and suppose point $\left(X^{*}, t^{*}\right)$ is a most-preferred choice of this voter in the feasible choice set (not shown). We argue first that no feasible points in the

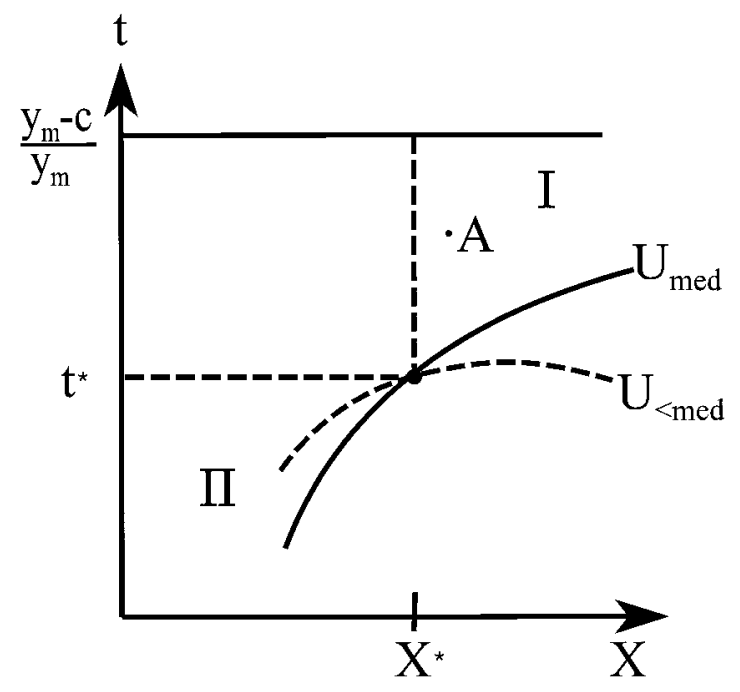

Fig. 7A.1 Illustration of proof of lemma 2 
$(X, t)$ plane are majority preferred to $\left(X^{*}, t^{*}\right)$, establishing it is an equilibrium point. The indifference curve $U_{\text {med }}$ and point $\left(X^{*}, t^{*}\right)$ partitions the $(X, t)$ plane into four regions. No points below $U_{\text {med }}$ are feasible choices, because this would contradict the median voter's preference for $\left(X^{*}, t^{*}\right)$. Point $\left(X^{*}, t^{*}\right)$ is preferred unanimously over all points in the rectangle with lower right-hand corner at $\left(X^{*}, t^{*}\right)$. Region I (see figure 7A.1) is made up of points above and including $U_{\text {med }}$ and with $X>X^{*}$ (e.g., point A). Since those with below-median preferences have flatter indifference curves through point $\left(X^{*}, t^{*}\right)$-for example, $U_{\text {med }}$ in figure 7A.1 - they $\operatorname{prefer}\left(X^{*}, t^{*}\right)$ to all points in region I. Since the median voter prefers $\left(X^{*}, t^{*}\right)$ or is indifferent (i.e., if the alternative point is on $\left.U_{\text {med }}\right)$, at least a weak majority prefers $\left(X^{*}, t^{*}\right)$. By an analogous argument, $\left(X^{*}, t^{*}\right)$ is not defeated by any points in region II. We have established that any most-preferred point of a voter with median preference is a majority voting equilibrium.

Any most-preferred point of the median voter is preferred by a strict majority over any other feasible point assuming a positive density of types in the vicinity of the median. A positive measure of households with $y / p$ in the vicinity of $y / p$ of the median voter will share the latter's strict preference, as will all those with lower or higher $y / p$ (or both). Hence, only most-preferred points of a voter with median preference are voting equilibria.

Lemma 2 points toward two potential cases of multiple equilibria. One has a gap in the density of the preference parameter at the 50th percentile and two median preference voters with distinct preferences. The other has multiple most-preferred points of a unique median preference voter. The former is ruled out by the (reasonable) parameter restriction

$$
y_{x} \geq \frac{p_{2}}{c} y_{m}
$$

and the latter will not arise in our model.

Applying lemma 2 to the neighborhood schooling case with no transportation cost and using equation (A1), one finds the pivotal voter in equation (7) of the text. For the case of choice with friction, it is straightforward to identify three exhaustive cases that identify income $y_{p 2}$ of a pivotal voter:

$$
\text { For } y^{*} \text { defined in } F_{y}\left(y^{*}\right)-F_{y}\left(y_{I}\right)=0.5 \text {, }
$$

$$
\begin{gathered}
y_{p 2}=y_{\mathrm{med}} \text { if } \frac{y_{\mathrm{med}}}{p_{2}} \geq \frac{y_{I}}{c} ; \\
y_{p 2}=y^{*} \text { if } \frac{y_{\mathrm{med}}}{p_{2}}<\frac{y_{I}}{c} \text { and } \frac{y^{*}}{p_{2}} \leq \frac{y_{m}}{c} ;
\end{gathered}
$$

or

$$
y_{p 2} \text { satisfies } F_{y}\left(y_{p 2}\right)-F_{y}\left(y_{I}\right)+F_{y}\left(\frac{c}{p_{2}} y_{p 2}\right)=0.5
$$




$$
\text { if } \frac{y_{\text {med }}}{p_{2}}<\frac{y_{I}}{c} \text { and } \frac{y^{*}}{p_{2}}>\frac{y_{m}}{c} \text {. }
$$

\section{Existence of Equilibrium in the Two-Jurisdiction Model}

Proposition A2. A sufficient condition for existence of differentiated equilibrium is

$$
\left\{\mathrm{y}_{\text {med }}-\mathrm{c}\left[1+\alpha\left(1-\frac{y_{\text {med }}}{y_{q 3}}\right)\right]\right\}\left(1-\frac{c}{y_{q 3}}\right)^{\alpha}
$$

$>\left\{\mathrm{y}_{\mathrm{med}}-\mathrm{c}\left[1+\alpha\left(1-\frac{\mathrm{y}_{\mathrm{med}}}{\mathrm{y}_{\mathrm{q} 1}}\right)\right]\right\}\left(1-\frac{\mathrm{c}}{\mathrm{y}_{\mathrm{q} 1}}\right)^{\alpha} \Omega$; where $\Omega \equiv\left(\frac{\theta_{1}}{\theta_{2}}\right)^{\gamma}\left(\frac{\bar{y}_{1}}{\overline{\mathrm{y}}_{2}}\right)^{\alpha}<1$,

and $\theta_{i}$ and $\bar{y}_{i}$ are calculated assuming income stratification with $y_{1}=y_{\text {med }}$ (recall equation [5]). Given that equation (A6) is satisfied and setting $p_{1}=c$, equilibrium (with differentiated schools) is unique. Two of many suffcient conditions for satisfaction of equation (A6) are (a) c sufficiently low; or (b) $\alpha<$ $y_{\text {med }} / y_{q 3}$.

Proof. To show existence, we must show equations (15)-(17) have a solution $\left(t_{1}, t_{2}, p_{1}, p_{2}\right)$ with $p_{i} \geq c, i=1,2$, and consistent with the residential preferences of proposition 6 . Clearance of housing markets will be implied. We show equation (A6) implies an equilibrium exists with $p_{1}=c$. Set $p_{1}=c$, substitute for $p_{1}$ in equation (15), and substitute equations (15) and (16) into equation (17):

$$
\begin{array}{r}
H\left(p_{2}\right)=\left\{y_{\mathrm{med}}-\mathrm{c}\left[1+\alpha\left(1-\frac{y_{\mathrm{med}}}{y_{q 1}}\right)\right]\right\}\left(1-\frac{c}{y_{q 1}}\right)^{\alpha} \Omega ; \\
\text { where } H\left(p_{2}\right) \equiv\left\{y_{\mathrm{med}}-p_{2}\left[1+\alpha\left(1-\frac{y_{\mathrm{med}}}{y_{q 3}}\right)\right]\right\}\left(1-\frac{p_{2}}{y_{q 3}}\right)^{\alpha} .
\end{array}
$$

Using $y_{q 3}>y_{\text {med }}$, observe that $H^{\prime}\left(p_{2}\right)<0$ for $p_{2}$ such that $H\left(p_{2}\right)>0$, and $H\left(p_{2}\right) \downarrow 0$ as $p_{2}$ rises. Note that the left-hand side of the inequality in condition (A6) is $H(c)$. The right-hand side of the inequality (A6) is positive since it has the same sign as the utility of median-income households when $p_{1}=$ $c$. It follows that, given equation (A6), a unique $p_{2}$ satisfying equation (A7) exists. Note, too, that this $p_{2}>c$. Hence, one can find a solution to equations (15)-(17) with $p_{i} \geq c, i=1,2$.

To show existence, it remains to be confirmed that the residential choices associated with the presumed allocation are actually optimal. This requires that $\Delta$ (defined in the proof of proposition 6) is increasing in $y$, or

$$
\left(1-t_{2}\right) q_{2}>\left(1-t_{1}\right) q_{1} .
$$

Rewrite the latter and substitute from equation (17):

$$
\frac{1-t_{2}}{1-t_{1}}>\frac{q_{1}}{q_{2}}=\frac{y_{\text {med }}\left(1-t_{2}\right)-p_{2}}{y_{\text {med }}\left(1-t_{1}\right)-p_{1}} \rightarrow p_{2}\left(1-t_{1}\right)>p_{1}\left(1-t_{2}\right) .
$$


Substitute from equations (15) and (16) and again rewrite the condition:

$$
p_{2}\left(1+\alpha \frac{p_{1}}{y_{q 1}}\right)>p_{1}\left(1+\alpha \frac{p_{2}}{y_{q 3}}\right) .
$$

Since $y_{q 3}>y_{q 1}, p_{2} \geq p_{1}$ is sufficient for satisfaction of equation (A10). We have shown $p_{2}$ exceeds $p_{1}=c$, completing the proof of existence.

We have already shown uniqueness given $p_{1}=c$. Sufficiency of condition (a) for equation (A6) uses $\Omega<1$. The left-hand side of the inequality (A6) converges to $y_{\text {med }}$ as $c \downarrow 0$, and the right-hand side converges to $\Omega y_{\text {med }}$. To show condition (b), let $g(y)$ denote the expression on the left-hand side of the inequality (A6) where $y=y_{q 3}$. With this notation, the inequality (A6) is $g\left(y_{q 3}\right)>\Omega g\left(y_{q 1}\right)$. It follows that the inequality is satisfied if $g(y)$ is an increasing function over $y \in\left[y_{q 1}, y_{q 3}\right]$. After straightforward manipulation one obtains

$$
g^{\prime}(y)=\frac{\alpha c y}{y^{2}(y-c)}\left(1-\frac{c}{y}\right) \alpha\left[c\left(\frac{y_{\mathrm{med}}}{y}-\alpha\right)+\alpha c \frac{y_{\mathrm{med}}}{y}\right] .
$$

Condition (b) is sufficient for $g^{\prime}>0$ in this range, proving the result.

Since equation (A6) involves nine parameters (counting $\theta_{1} / \theta_{2}$ as one), it is not particularly intuitive. However, condition (A6) is easily satisfied, for example, as in the two sufficient conditions for its satisfaction. One can see by inspection that if the construction cost $c$ of a house is sufficiently low equation (A6) will be satisfied. Roughly, the sufficient conditions (and other sufficient conditions) ensure that voting effects do not contradict the sorting implications of peer effects. For example, as $c$ declines toward zero, $t_{2}<t_{1}$ is implied (use equations [15] and [16] and that $p_{1}=c$ ), and tax effects reinforce income sorting. Note also that as $\Omega$ declines, it is more likely that equation (A6) will be satisfied. Hence, high correlation of $(y, b)$, implying relatively low $\theta_{1} / \theta_{2}$, favors existence of stratified equilibrium. Moreover, equation (A6) is not necessary for existence of equilibrium. Absent satisfaction of equation (A6), $p_{1}>p_{2}$ in an equilibrium. It appears that this is possible (but we have not worked out any such examples). Such an equilibrium would have a much higher tax rate in neighborhood 2 than in neighborhood 1 , reflecting a relatively high $y_{q 3}$, and such that a lower housing price in neighborhood 2 is necessary to keep the median-income household indifferent to residence.

\section{An Interjurisdictional Choice Policy}

The model is the same as in section 7.4.3 of the text except for the school choice policy. Following residential choice, households commit to attend school in their own neighborhood or the other one. Every household then votes for the tax-expenditure pair with those committed to the same school, and with tax base consisting of that school's households. Hence, those that attend a school comprise a jurisdiction independent of their residences. We assume transportation costs are negligible (zero). 
We show that equilibrium will probably be the same as when there is frictionless choice across two neighborhoods of one jurisdiction. Since school and thus jurisdictional membership is independent of the first-stage residential choice, housing prices must be the same in the two neighborhoods. Hence, $p_{2}=p_{1}=c$, as we have argued earlier that $p_{1}=c$ is a sensible convention.

The difference in utility if school and jurisdiction 2 are selected from the utility if school and jurisdiction 1 are selected is given by

$$
\begin{aligned}
\Delta & \equiv b^{\beta}\left\{\left[y\left(1-t_{2}\right)-c\right] q_{2}-\left[y\left(1-t_{1}\right)-c\right] q_{1}\right\} \\
& =b^{\beta}\left\{\left[\left(1-t_{2}\right) q_{2}-\left(1-t_{1}\right) q_{1}\right] y-c\left(q_{2}-q_{1}\right)\right\} .
\end{aligned}
$$

Assuming $q_{2} \geq q_{1}$ with no loss in generality, we see using equation (A11) that equilibrium has either (a) $q_{2}>q_{1} ; t_{2}>t_{1}$; and income stratification; (b) $q_{2}=$ $q_{1} ; t_{2}=t_{1}$; and all households indifferent to their school/jurisdictional choice. If $q_{2}>q_{1}$, then income stratification is implied by the linearity of $\Delta$ in $y$. For this case, if not $t_{2}>t_{1}$, then school/jurisdiction 2 would be preferred by all. We emphasize that the conditions in (a) are merely selected necessary conditions for a stratified equilibrium; they are not sufficient. If $q_{2}=q_{1}$ and $t_{2} \neq t_{1}$, then equation (A11) would imply that everyone prefers the school/ jurisdiction with lower tax rate. (If everyone were in one school, then a rich type with a bright child would be better off attending his own school.)

For realistic parameterizations, stratified equilibrium will not exist. We show why with some intuitive arguments, in lieu of a (more lengthy) computational analysis. Assume that there is a stratified equilibrium. Then $q_{2}$ $>q_{1}$ because the rich school/jurisdiction has a better peer group and a wealthier tax base $\left(t_{2}>t_{1}\right.$ is a necessary condition, recall). Such an equilibrium would have an indifferent household (income) as well, for whom equation (A11) would vanish. However, it is very difficult to satisfy all these conditions. The reason is that the tax rate that will be selected in equilibrium by the rich will not typically be high enough to keep out the poorer types, and there is no longer a housing price differential that can serve as a deterrent.

To see this, first suppose that $c$ is small. Then the equilibrium tax rates will hardly differ. Equation (9) in the text describes the tax rate in each jurisdiction if $y_{p 1}$ is replaced by the median income in the jurisdiction. As $c \rightarrow 0, t_{1}$ $\rightarrow t_{2}$ for any allocation, and no indifferent household can exist. An analogous argument precludes stratified equilibrium as $\alpha \rightarrow 0$.

Another way to see the difficulty in obtaining a stratified equilibrium is by a graphic analysis. Assume initially that $E[b \mid y]$ is invariant to $y$. We will show that it is quite difficult to obtain a stratified equilibrium and then show that $E[b \mid y]$ that increases in $y$ makes it more difficult.

Assuming a stratified equilibrium, figure 7A.2 depicts in the $(X, t)$ plane a "voting indifference curve" of the pivotal voter in the poor school/juris- 


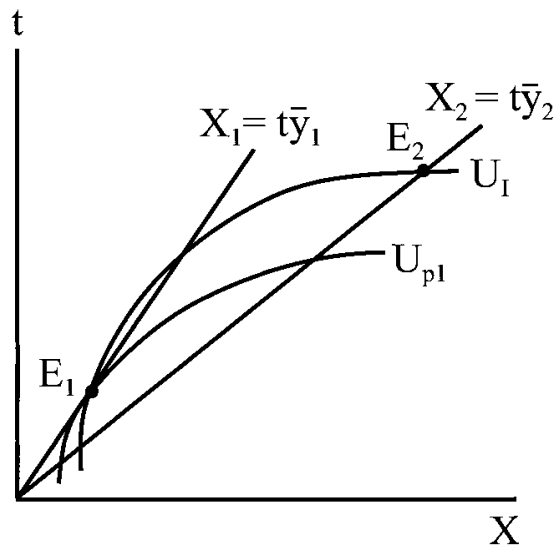

Fig. 7A.2 Illustration of analysis of interjurisdictional choice policy

diction $\left(U_{p 1}\right)$, an indifference curve of the type indifferent between schools $\left(U_{I}\right)$, and the budget constraints of the two schools/jurisdictions. (The indifference curves are those discussed in and preceding lemma 1.) $E_{1}$ shows the equilibrium expenditure per student and tax rate in school/jurisdiction 1. The indifferent household has indifference curve through $E_{1}$ that is steeper than is the pivotal voter's because the former type has higher income (see lemma 1). (Note that in the extreme of $c=0$, the indifference mappings of all types would be the same, again precluding equilibrium, as we will see momentarily.) Equilibrium in school/jurisdiction 2 would have to be at point $E_{2}$ so that "type I" is indifferent. Hence, the indifference curve of the pivotal voter in school/jurisdiction 2 (i.e., the median-income type there) would need to be tangent to $X_{2}=t \bar{y}_{2}$ at $E_{2}$. This indicates that preferences for $X$ need to rise precipitously with income to obtain such an equilibrium. If, for example, $\alpha$ is small, then this will not occur.

If we now let $E[b \mid y]$ increase with $y$, then the difficulty is exacerbated. The preference mappings are unchanged (due to the Cobb-Douglas specification), but the values of utility are higher in jurisdiction 2 than in jurisdiction 1 . Utility at $E_{2}$ in school 2 is then higher than utility at $E_{1}$ in school 1 for type I. This implies that the equilibrium point in jurisdiction 2 is higher up $X_{2}=t_{2} \bar{y}_{2}$ than $E_{2}$.

Given that equilibrium of type (a) above does not exist, then equilibrium is of type (b). In such an equilibrium, everyone is indifferent to residential and school/jurisdictional choice. Hence, assume types randomize over their choices, all with the same probabilities. This implies schools and jurisdictions that are homogeneous: That is, each school's distribution of types is the same as the population distribution. The outcome is the same as with frictionless choice and one jurisdiction. 


\section{Proof of Proposition 9}

Proposition 9 is essentially an application of results in Epple and Romano $(1998,1999)$. Here we sketch proofs for the reader's convenience.

A. This is the "strict hierarchy result" in the papers just cited, developed assuming fixed expenditures across schools in Epple and Romano (1998) and extended to variation in expenditure in Epple and Romano (1999). The proof proceeds as follows. Assume $q_{1}=q_{2}$ and show a Pareto improvement is feasible. First show that $q_{1}=q_{2}$ implies $X_{1}=X_{2}$ and $\theta_{1}=\theta_{2}$ using quasiconcavity of $q(X, \theta)$. If, say, $\theta_{2}>\theta_{1}$, then $X_{2}<X_{1}$ and $q_{\theta} / q_{x}$ is higher in school 1 than in school 2. Using proposition 8 and the definition of $\mathrm{SMC}_{i}$, it is implied that there is an ability threshold $B$, such that all types with $b>$ $(<) B$ would choose to attend school 1(2). This contradicts $\theta_{2}>\theta_{1}$.

Having established that $q_{1}=q_{2}$ implies $X_{1}=X_{2}$ and $\theta_{1}=\theta_{2}$, we can regard the schools as having homogeneous student bodies (with respect to both $b$ and $y$ ). Then it is shown that one can engender a Pareto improvement by having the schools exchange students in a particular way that leads one school to be of higher quality, with more able and also richer students, and the opposite for the other school. The Pareto improvement does not require changes in $X_{1}$ or $X_{2}$. Mathematically, this is somewhat involved, since it relies on second-order effects (as first-order effects vanish), so we refer the reader to the proof of proposition 1 in Epple and Romano (1998). The intuition is, however, not too complicated: Those in the improved school are obviously better off. Those in the school that has deteriorated are better off because the contribution to costs of the departed students is relatively low due to their high abilities and thus low SMC, and the reduced quality is of relatively low "cost" because the student body becomes relatively poor and cares less about quality.

B. Given $q_{2}>q_{1}$, income stratification follows by equation (1) and because prices depend only on student ability (see equation [19] in the text). That is, for any given ability, if there is a household indifferent to the schools when $r_{i}=\mathrm{SMC}_{i}, i,=1,2$, then all types having higher (lower) income strictly prefer school 2 (1). (If there is no indifferent type, then all types with that ability attend one of the two schools.)

The indifferent set in equation (22) is found simply by equating utilities given $r_{i}=\mathrm{SMC}_{i}$ and using the definition of $\eta_{i}$.

C. Equation (23) is found from equation (20) and the analogue for $X_{2}$, again using $r_{i}=\mathrm{SMC}_{i}, i=1,2$. Specifically, for $i=1$,

$$
\begin{aligned}
\frac{\partial U^{1}(b, y) / \partial X}{\partial U^{1}(b, y) / \partial y} & =\frac{\alpha}{X_{1}}\left(y-c-r_{1}\right) \\
& =\frac{\alpha}{X_{1}}\left[y-c-X_{1}-\frac{q_{\theta}}{q_{x}}\left(\theta_{1}-\mathrm{b}\right)\right]
\end{aligned}
$$




$$
\begin{aligned}
& =\frac{\alpha}{X_{1}}\left[y-c-X_{1}-\frac{\gamma X_{1}}{\alpha \theta_{1}}\left(\theta_{1}-\mathrm{b}\right)\right] \\
& =\frac{\alpha}{X_{1}}(y-c)-\alpha-\frac{\gamma}{\theta_{1}}\left(\theta_{1}-b\right),
\end{aligned}
$$

the second-to-last equality using

$$
\frac{q_{\theta}}{q_{x}}=\frac{\gamma X}{\alpha \theta} .
$$

Then substitute equation (A12) into equation (20) and rearrange, while noting that the density of types in school 1 is given by $A f / \iint A f d b d y . X_{2}$ is found analogously.

The result in equation (24) is found by substituting equation (23) into equation (A13).

D, E. These are efficiently proved together. Note from equation (22) that the boundary locus in the $(b, y)$ plane is linear (see figure 7.6 for an example), so that, given we have established income stratification, ability stratification corresponds to a downward-sloping boundary locus. Suppose this locus is not downward sloping. Then, for $E[b \mid y]$ constant in $y, \theta_{2} \leq \theta_{1}$. Hence, $q_{2}>q_{1}$ implies $X_{2}>X_{1}$. This implies $\eta_{2}>\eta_{1}$, which by equation (22) implies a downward-sloping boundary locus - a contradiction.

Hence, the boundary locus is downward sloping, obviously also implying $\theta_{2}>\theta_{1}$.

F. $\eta_{i} q_{i}=\gamma / \alpha \mathrm{X}_{i}^{1+\alpha} \theta_{i}^{\gamma-1}$. By part $\mathrm{E}$ of this proposition and equation (22), $\eta_{2} q_{2}>\eta_{1} q_{1}$. Using part $\mathrm{D}$ of this proposition, then, $X_{2}>X_{1}$ whenever $\gamma<1$.

\section{References}

Arnott, Richard, and John Rowse. 1987. Peer group effects and educational attainment. Journal of Public Economics 32 (3): 287-305.

Barrow, Lisa. 1999. School choice through relocation: Evidence from the Washington, D.C., area. Federal Reserve Bank of Chicago Working Paper 99-7. Chicago: Federal Reserve Bank of Chicago, March.

Benabou, Roland. 1993. Workings of a city: Location, education, and production. Quarterly Journal of Economics 108 (3): 619-52.

. 1996. Equity and efficiency in human capital investment: The local connection. Review of Economic Studies 63:237-64.

2000. Unequal societies: Income distribution and the social contract. American Economic Review 90 (March): 96-129.

Betts, Julian. 1996. Is there a link between school inputs and earnings? Fresh scrutiny of an old literature. In Does money matter? The effect of school resources on student achievement and adult success, ed. Gary Burtless, 141-91. Washington, D.C.: Brookings Institution. 
Black, Sandra E. 1999. Do better schools matter? Parental valuation of elementary education. Quarterly Journal of Economics 114 (2): 577-600.

Brueckner, Jan K. 2000. A Tiebout/tax-competition model. Journal of Public Economics 77 (August): 285-306.

Caucutt, Elizabeth M. 2002. Educational vouchers when there are peer group effects: Size matters. International Economic Review 43 (February): 195-222.

Cullen, Julie B., Brian A. Jacob, and Steven D. Levitt. 2000. The impact of school choice on student outcomes: An analysis of the Chicago public schools. NBER Working Paper no. 7888. Cambridge, Mass.: National Bureau of Economic Research, September.

de Bartolome, Charles A. M. 1990. Equilibrium and inefficiency in a community model with peer group effects. Journal of Political Economy 98 (1): 110-33.

1997. What determines state aid to school districts. Journal of Policy Analysis and Management 16:32-47.

Durlauf, Steven N. 1996. A theory of persistent income inequality. Journal of Economic Growth 1 (March): 75-93.

Eden, Ben. 1992. How to subsidize education: An analysis of voucher systems. University of Iowa, Department of Economics. Working Paper.

Ellickson, Bryan. 1971. Jurisdictional fragmentation and residential choice. American Economic Review Papers and Proceedings 61 (May): 334-39.

Epple, Dennis, David Figlio, and Richard Romano. Forthcoming. Competition between private and public schools: Testing stratification and pricing predictions. Journal of Public Economics.

Epple, Dennis, Radu Filimon, and Thomas Romer. 1984. Equilibrium among local jurisdictions: Toward an integrated treatment of voting and residential choice. Journal of Public Economics 24 (August): 281-308.

Epple, Dennis, Elizabeth Newlon, and Richard Romano. 2002. Ability tracking, school competition, and the distribution of educational benefits. Journal of Public Economics 83 (January): 1-48.

Epple, Dennis, and Richard Romano. 1995. Public school choice and finance policies, neighborhood formation, and the distribution of educational benefits. University of Florida, Department of Economics Working Paper. July 1995.

- 1996. Ends against the middle: Determining public service provision when there are private alternatives. Journal of Public Economics 62:297-325.

- 1998. Competition between private and public schools, vouchers and peergroup effects. American Economic Review 88 (1): 33-62.

. 1999. Educational vouchers and cream skimming. University of Florida, Department of Economics. Working Paper.

. 2000. On Pareto efficient pricing and peer groups in schools. University of Florida, Department of Economics Working Paper, June.

Epple, Dennis, and Thomas Romer. 1991. Mobility and redistribution. Journal of Political Economy 99 (4): 828-58.

Evans, William N., Wallace E. Oates, and Robert M. Schwab. 1992. Measuring peer group effects: A study of teenage behavior. Journal of Political Economy 100:96691.

Fernández, Raquel. 1997. Odd versus even: Comparative statics in multicommunity models. Journal of Public Economics 65 (2): 789-812.

Fernández, Raquel, and Richard Rogerson. 1996. Income distribution, communities, and the quality of public education. Quarterly Journal of Economics 111 (1): 135-64.

1997a. Education finance reform: A dynamic perspective. Journal of Policy Analysis and Management 16 (1): 67-84. 
1997b. Keeping people out: Income distribution, zoning, and quality of public education. International Economic Review 38 (1): 23-42.

1998. Public education and income distribution: A dynamic quantitative evaluation of education finance reform. American Economic Review 88 (4): 81333.

Friedman, Milton. 1962. Capitalism and freedom. Chicago: University of Chicago Press.

Gans, J. S., and M. Smart. 1996. Majority voting with single-crossing preferences. Journal of Public Economics 59:219-37.

Glaeser, Edward, Matthew Kahn, and Jordon Rappoport. 2000. Why do the poor live in cities? NBER Working Paper no. 7636. Cambridge, Mass.: National Bureau of Economic Research, April.

Glomm, Gerhard, and B. Ravikumar. 1992. Public versus private investment in human capital: Endogenous growth and income inequality. Journal of Political Economy 100:813-34.

Gold, Steven D., David M. Smith, and Stephen B. Lawton, eds. 1995. Public school finance programs of the United States and Canada 1993-94. Albany, N.Y.: American Education Finance Association and Center for the Study of the States, Nelson A. Rockefeller Institute of Government, State University of New York.

Goodspeed, Timothy. 1989. A re-examination of the use of ability to pay taxes by local governments. Journal of Public Economics 38 (April): 319-42.

Hanushek, Eric. 1986. The economics of schooling: Production and efficiency in public schools. Journal of Economic Literature 24 (3): 1141-77.

1997. Assessing the effects of school resources on student performance: An update. Educational Evaluation and Policy Analysis 19 (Summer): 141-64.

Henderson, Vernon, Peter Mieszkowski, and Yvon Sauvageau. 1978. Peer group effects in educational production functions. Journal of Public Economics 10 (1): 97-106.

Hoxby, Caroline Minter. 1995. Is there an equity-efficiency trade-off in school finance? Tiebout and a theory of the local goods producer. NBER Working Paper no. 5265. Cambridge, Mass.: National Bureau of Economic Research, September.

2000a. Does competition among public schools benefit students and taxpayers? Evidence from natural variation in school districting. American Economic Review 90 (5): 1209-38.

. 2000b. Peer effects in the classroom: Learning from gender and race variation. NBER Working Paper no. 7867. Cambridge, Mass.: National Bureau of Economic Research, August.

Inman, Robert P. 1978. Optimal fiscal reform of metropolitan schools: Some simulation results. American Economic Review 68 (1): 107-22.

Manski, Charles F. 1992. Educational choice (vouchers) and social mobility. Economics of Education Review 11 (4): 351-69.

McMillan, Robert. 1999. Heterogeneity, competition, and public school productivity. Stanford University, Department of Economics. Working Paper, May.

2000. Parental pressure and private school competition: An empirical analysis of the determinants of public school quality. University of Toronto, Department of Economics. Mimeograph.

Moreland, Richard L., and John M. Levine. 1992. The composition of small groups. In Advance in group processes, vol. 9, eds. B. Markovsky, C. Ridgeway, and H. Walker, 237-80. Greenwich, Conn.: JAI Press.

Murray, Sheila E., William N. Evans, and Robert M. Schwab. 1998. Education finance reform and the distribution of education resources. American Economic Review 88 (4): 789-812. 
Neal, Derek A., and William R. Johnson. 1996. The role of premarket factors in black-white wage differences. Journal of Political Economy 104 (5): 869-95.

Nechyba, Thomas. 1999. School finance induced migration patterns: The case of private school vouchers. Journal of Public Economic Theory 1 (1): 5-50. 2000. Mobility, targeting, and private-school vouchers. American Economic Review 90 (1): 130-46.

Rees, Nina Shokraii. 2000. School choice 2000: What's happening in the states. Washington, D.C.: The Heritage Foundation.

Roberts, K. W. S. 1977. Voting over income tax schedules. Journal of Public Economics 8:329-40.

Rothschild, Michael, and Lawrence J. White. 1995. The analytics of the pricing of higher education and other services in which the customers are inputs. Journal of Political Economy 103 (3): 573-623.

Sacerdote, Bruce. 2000. Peer effects with random assignment: Results for Dartmouth roommates. NBER Working Paper no. 7469. Cambridge, Mass.: National Bureau of Economic Research. January.

Silva, Fabio, and Jon Sonstelie. 1995. Did Serrano cause a decline in school spending? National Tax Journal 48 (2): 199-215.

Solon, Gary. 1992. Intergenerational income mobility in the United States. American Economic Review 82 (3): 393-409.

Summers, Anita, and Barbara L. Wolfe. 1977. Do schools make a difference? American Economic Review 67 (4): 639-52.

Tiebout, C. 1956. A pure theory of local expenditures. Journal of Political Economy 65:416-24.

Toma, Eugenia. 1996. Public funding and private schooling across countries. Journal of Law and Economics 39 (1): 121-48.

U.S. Department of Education, National Center for Education Statistics. 1994. Common core of data. Washington, D.C.: U.S. Department of Education, National Center for Education Statistics.

1996. Public school choice programs, 1993-94: Availability and student participation. Washington, D.C.: U.S. Department of Education, National Center for Education Statistics.

Westhoff, F. 1977. Existence of equilibria in economies with a local public good. Journal of Economic Theory 14:84-112.

Zimmer, Ron W., and Eugenia Toma. 1999. Peer effects in private and public schools across countries. Journal of Policy Analysis and Management 19:75-92.

Zimmerman, David J. 1992. Regression toward mediocrity in economic stature. American Economic Review 82 (3): 409-29. 